Article

\title{
Developments in Tall Wood and Hybrid Buildings and Environmental Impacts
}

\author{
Asif Iqbal
}

check for

updates

Citation: Iqbal, A. Developments in Tall Wood and Hybrid Buildings and Environmental Impacts. Sustainability 2021, 13, 11881. https://doi.org/ $10.3390 /$ su132111881

Academic Editor: Rishi Gupta

Received: 16 September 2021

Accepted: 18 October 2021

Published: 27 October 2021

Publisher's Note: MDPI stays neutral with regard to jurisdictional claims in published maps and institutional affiliations.

Copyright: (C) 2021 by the author. Licensee MDPI, Basel, Switzerland. This article is an open access article distributed under the terms and conditions of the Creative Commons Attribution (CC BY) license (https:/ / creativecommons.org/licenses/by/ $4.0 /)$.
School of Engineering, University of Northern British Columbia, Prince George, BC V2N 4Z9, Canada; asif.iqbal@unbc.ca

\begin{abstract}
Wood has been gaining popularity as a building material over the last few decades. There has been significant progress in technology during this period to push the limits of wood construction. At the same time, it has become more economically competitive to build with wood beyond lowrises. As a result, there has been a noteworthy shift in public perception in terms of acceptance of wood as a material for high-rise buildings. There is a growing list of tall wood buildings that have been constructed in different continents over the last decade. With worldwide population growth and increased urbanization, the trend is expected to continue. Considerable urgency for using sustainable resources to tackle the threat of climate change has resulted in a surge in demand as well as applications in recent decades. This paper reviews the significant technical advances that have contributed to those achievements and are expected to facilitate further developments.
\end{abstract}

Keywords: tall wood buildings; hybrid structures; sustainable construction

\section{Introduction}

Wood has been gaining popularity as a building's structural material over the last few decades. Significant progress in technology has been made during this period to push the limit of wood construction. At the same time, it has become more economically competitive in general over long periods to build with wood beyond low-rises. As a result, there has been a noteworthy shift in public perception in terms of acceptance of wood as a material for high-rise buildings. There is a growing list of tall wood buildings that have been constructed in different continents over the last decade. With worldwide population growth and increased urbanization, the trend is expected to continue. The significant technical advances that have contributed to those achievements and are expected to facilitate further developments are presented here. Advanced processing and manufacturing techniques, as well as mechanized mass production and fabrication facilities, are offering materials of improved quality - known as engineered wood products—at competitive prices and large quantities.

The construction practice is progressing fast, implementing efficient design developed through better understanding of material behavior and the utilization of sophisticated modelling tools and new approaches in analysis. Structural systems previously considered impractical with wood are now feasible with members made of wood-based materials that have improved engineering properties. New structural concepts and construction techniques have also been proposed that can enable applications to meet demands from greater building heights and additional challenges due to significant wind and seismic loading. The idea of hybrid structures involving more than one material such as wood in combination with steel and/or concrete is gaining more and more acceptance within the general engineering community [1]. Publications of design guidelines and code updates complemented by adjustments in policies and regulations have been facilitating widespread adoption of the latest technology [2,3].

Along with Europe, North America, particularly Canada, is forging ahead with research and implementations of tall wood buildings (Figure 1). Over two decades of 
experience have given designers confidence to push for greater heights. Unlike most of Europe, the entire Pacific coast of North America is a high seismic area (Figure 2) and significant resources have been invested to find solutions for timber structures in the region. Wood has particular advantages in such areas as a lightweight material and thereby producing significantly less inertia forces during earthquakes, as well as being more flexible and less likely to suffer significant damage with a much lower stiffness value compared to concrete and steel. Wood being a combustible material, there are some concerns with fire safety, but with current technology, modern wood building can be designed to achieve necessary fire ratings for practical purposes.

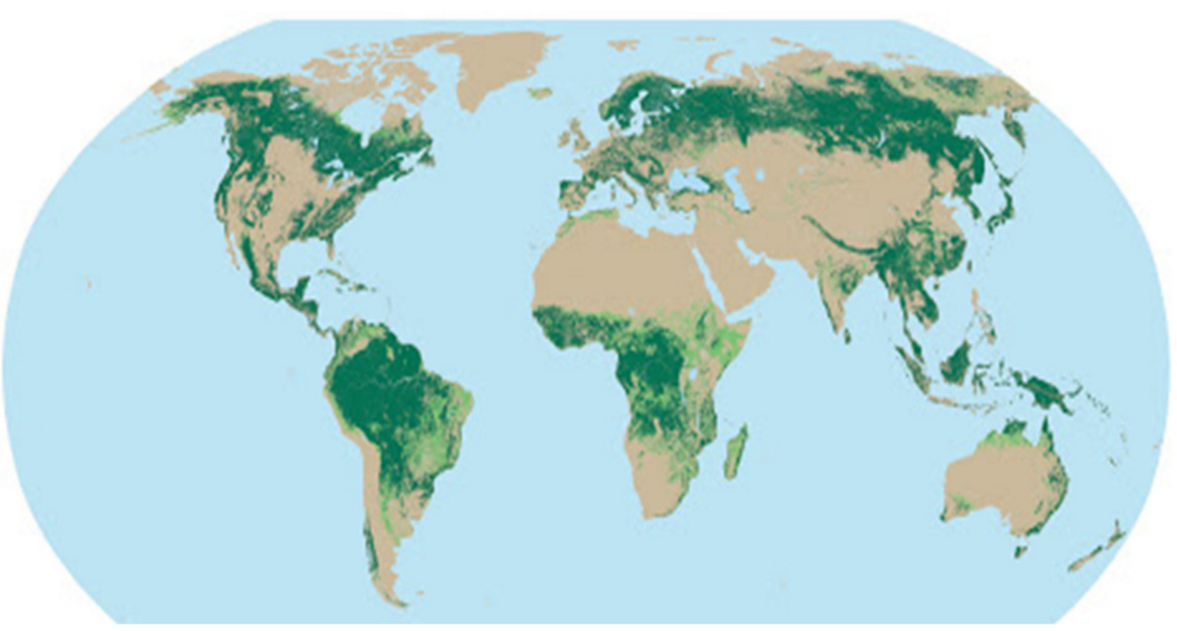

Figure 1. Major forestry regions of the world, indicated in green (Source: FAO, http:/ /www.fao. org/forest-resources-assessment/past-assessments/fra-2005/maps-and-figures/en/, accessed on 5 September 2021).

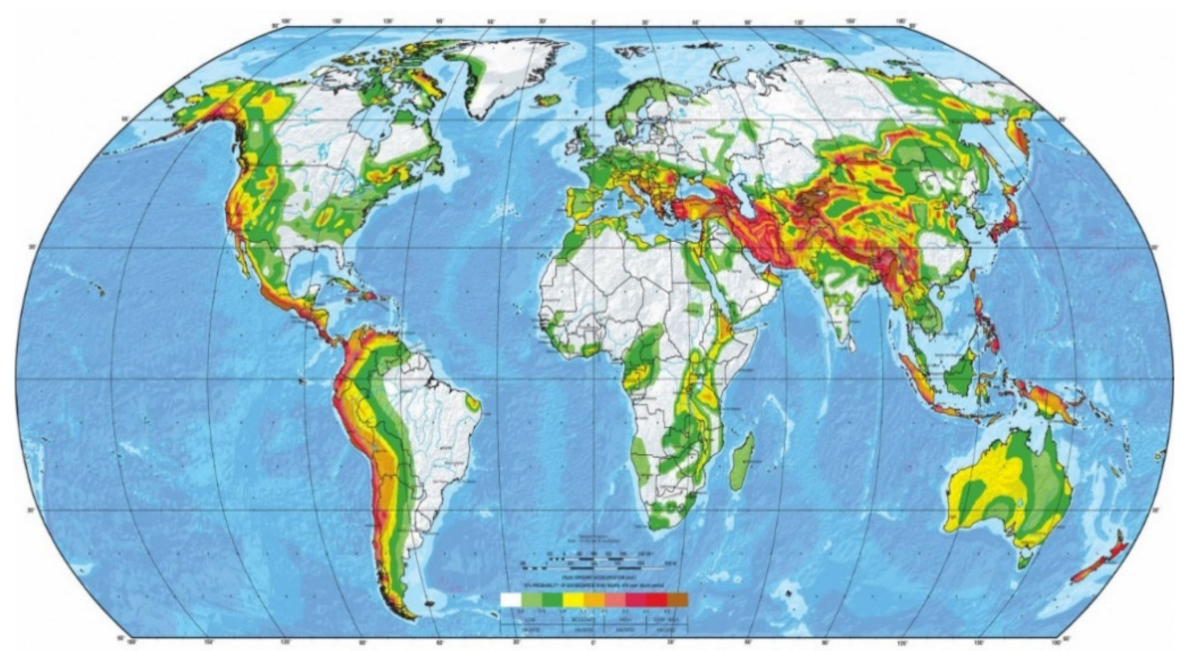

Figure 2. Seismic regions of the world (Source: Global Seismic Hazard Assessment Program, http: / / static.seismo.ethz.ch/GSHAP/global/, accessed on 5 September 2021).

Recent trends of urbanization are creating the need for the design and construction of modern buildings for high density living across North America. There is also increasing interest in building with locally available, sustainable material such as wood. Engineered wood products have been successfully used in other countries for such construction over the last two decades, and it has been also attracting considerable attention in the urban regions of North America. Strong governmental support to utilize timber has helped to put Canada in a leading position in North America for tall wood building construction. The manufacturing and utilization of engineered wood products have been gaining momentum 
in Canada over the past few years, with some of the design approaches imported from Western Europe.

\section{Scope and Objectives}

This chapter presents a review of history and background of recent mid-to-highrise wood buildings and progression towards modern taller high-rises. The demand has increased steadily due to growth and the increased urbanization of population. Factors such as construction practices and fire safety regulations have played a major role in the developments over the last century. With major advances in computational capabilities for analysis and design, developments of materials such as engineered wood products as well fabrication and production facilities have opened up possibilities for wood to compete with other traditional materials for the cost-effective construction of high-rise buildings. Different aspects of the latest technological developments are discussed with practical examples. Major initiatives to promote the practices are highlighted. Current trends and a brief outlook towards near future directions are presented in this chapter.

\section{Sustainability and Environmental Impact}

As a naturally grown material with carbon sequestration properties, wood has significant appeal as a sustainable material. Figure 3 illustrates the relative advantages of wood through comparing options with different materials, including one with the maximum amount of wood used called TimberPlus, from an emissions point of view. With continued supply from designated sources, the use of wood in the construction industry has been carefully managed through utilization as structural members. The wood can be harvested commercially while maintaining a steady and balanced level of supply and demand. Environmental sustainability is thus maintained by allowing the forests to replenish the harvested wood. In the face of increasing threats of global warming and associated climate change, it has become more important than ever to reduce carbon emissions and use alternative materials for construction, similar to all other types of human activities. With a lesser likelihood of damage and collapse, wood has potentially excellent long-term performance, which also contributes to sustainability. Several studies in different countries have indicated that wood is competitive with steel and concrete in terms of material cost, allowing it to be considered as a practical option for high-rise construction.

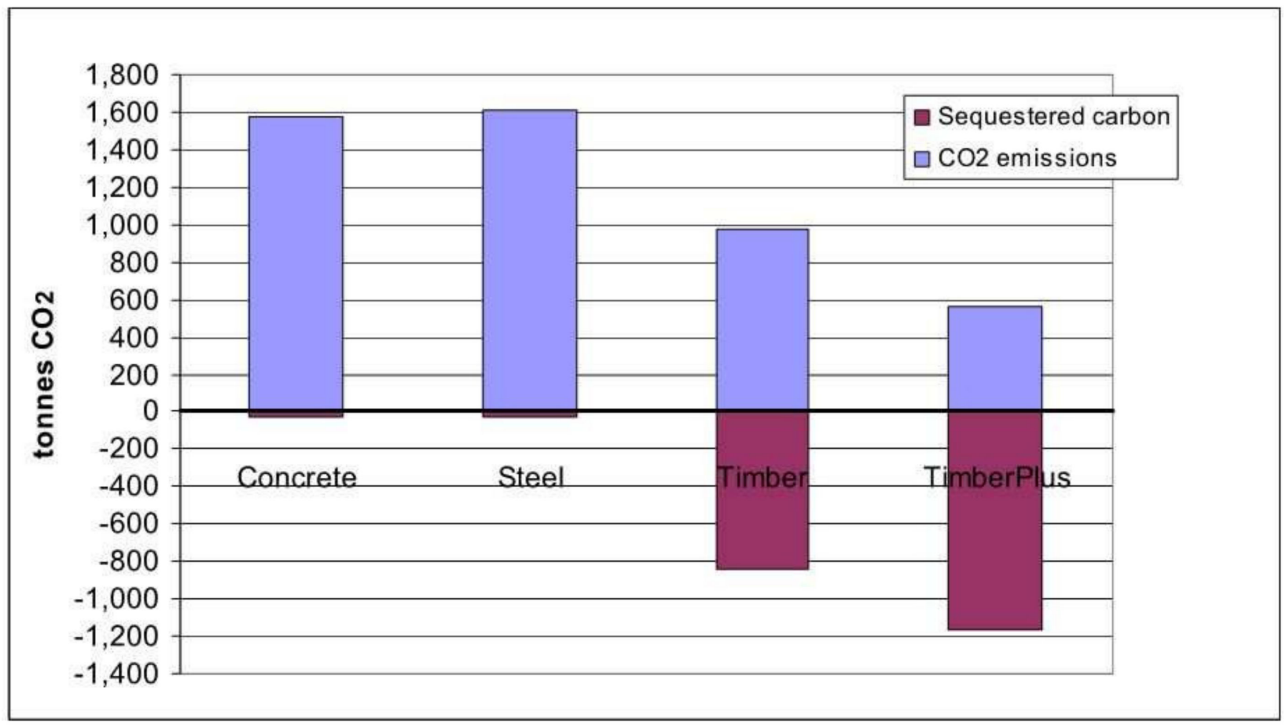

Figure 3. Relative emissions with different materials.

The production of cement for concrete creates large amounts of $\mathrm{CO}_{2}$ that are emitted into the atmosphere and contributes to global warming or climate change and large amounts of air pollution. The use of a renewable building material such as wood can 
reduce the amount of concrete required to construct mid- to high-rise buildings and reduce these environmental impacts. Wood also stores carbon, making it an environmentally friendly building material. The stored carbon is released back into the atmosphere at the end of the material's life cycle when the material is burned as fuel or deteriorates.

\section{Re-Emergence of Tall Wood Buildings}

One of the biggest challenges for multistory wood buildings is the negative perception regarding fire safety in terms of the time for the evacuation of occupants without compromising the safety of the structure. To overcome this, necessary technical information is provided as to how these buildings can ensure adequate fire protection to achieve solutions acceptable to the National Building Code of Canada (NBCC) for non-combustible construction [1]. The code even addresses issues of the safety of firefighters and other emergency personnel responding to a building fire.

With the increasing number of stories and heights, the lateral loads caused by wind and earthquakes become more significant. The design of tall structures requires additional attention and special connection detailing to resist lateral load, especially for high seismic demand. For multistore buildings, lateral deflection and acceleration criteria have to be met while maintaining global stability demands, which is even more important for tall wood buildings. Western USA and Canada are major forestry regions and home to several historic tall wood buildings (Figure 4). The Murray Groove Building in London and Forte Apartments in Melbourne, Australia (Figure 5) are prime examples of modern tall wood buildings. Along with Europe and the USA, Canada is particularly forging ahead with research and implementations of tall wood buildings (Figures 6 and 7). The experience gained over last two decades has given designers enough confidence to push for greater heights. Unlike much of Europe, the entire Pacific coast of North America is a high seismic region, and significant resources have been invested to find solutions for timber structures in the region (Figure 7).

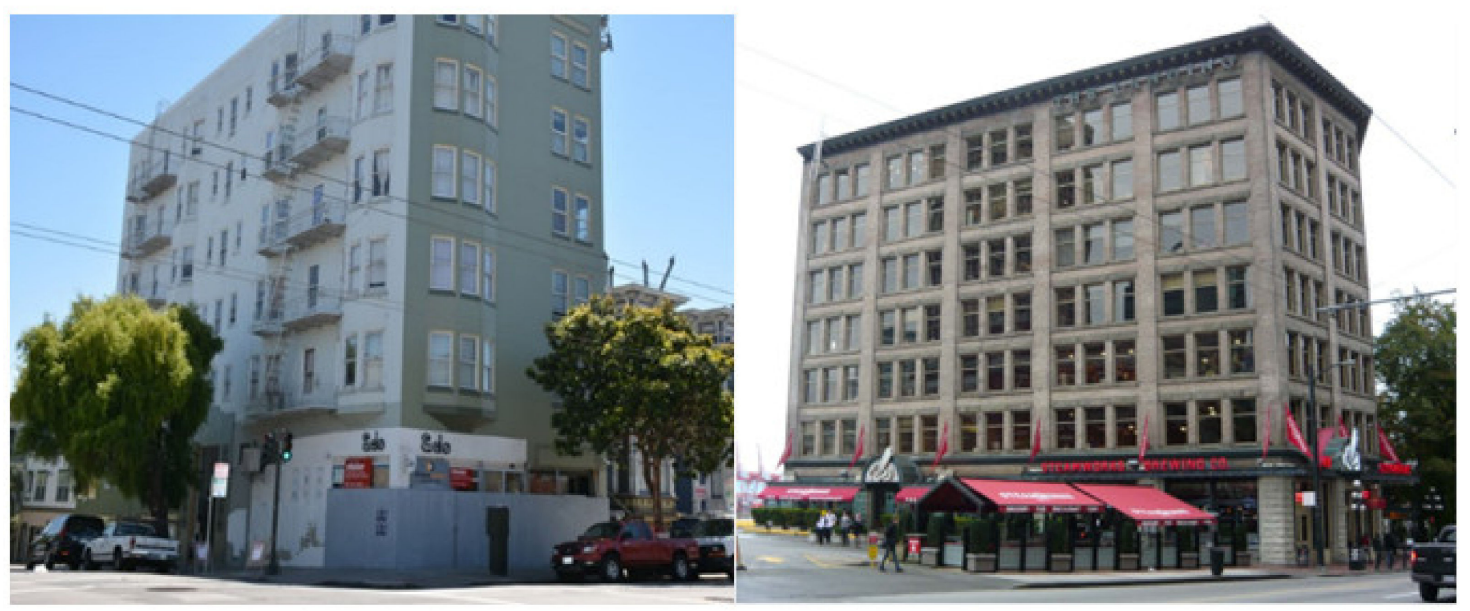

(a)

(b)

Figure 4. Historical wood buildings in San Francisco (a) and Vancouver, Canada (b) (Photo in public domain). 


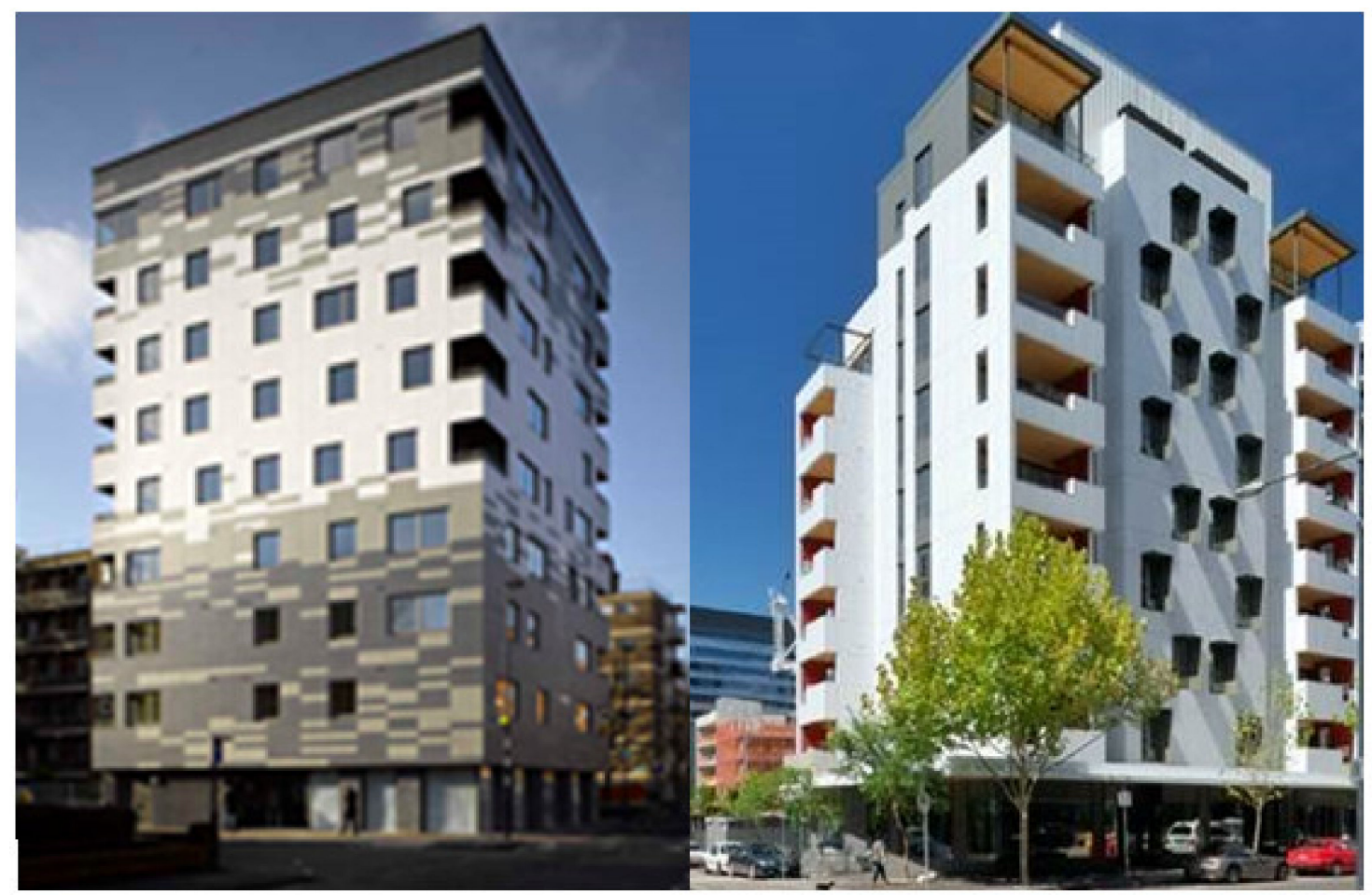

(a)

(b)

Figure 5. Murray Groove, London (a) and Forte Apartments, Melbourne (b) (Photo in public domain).

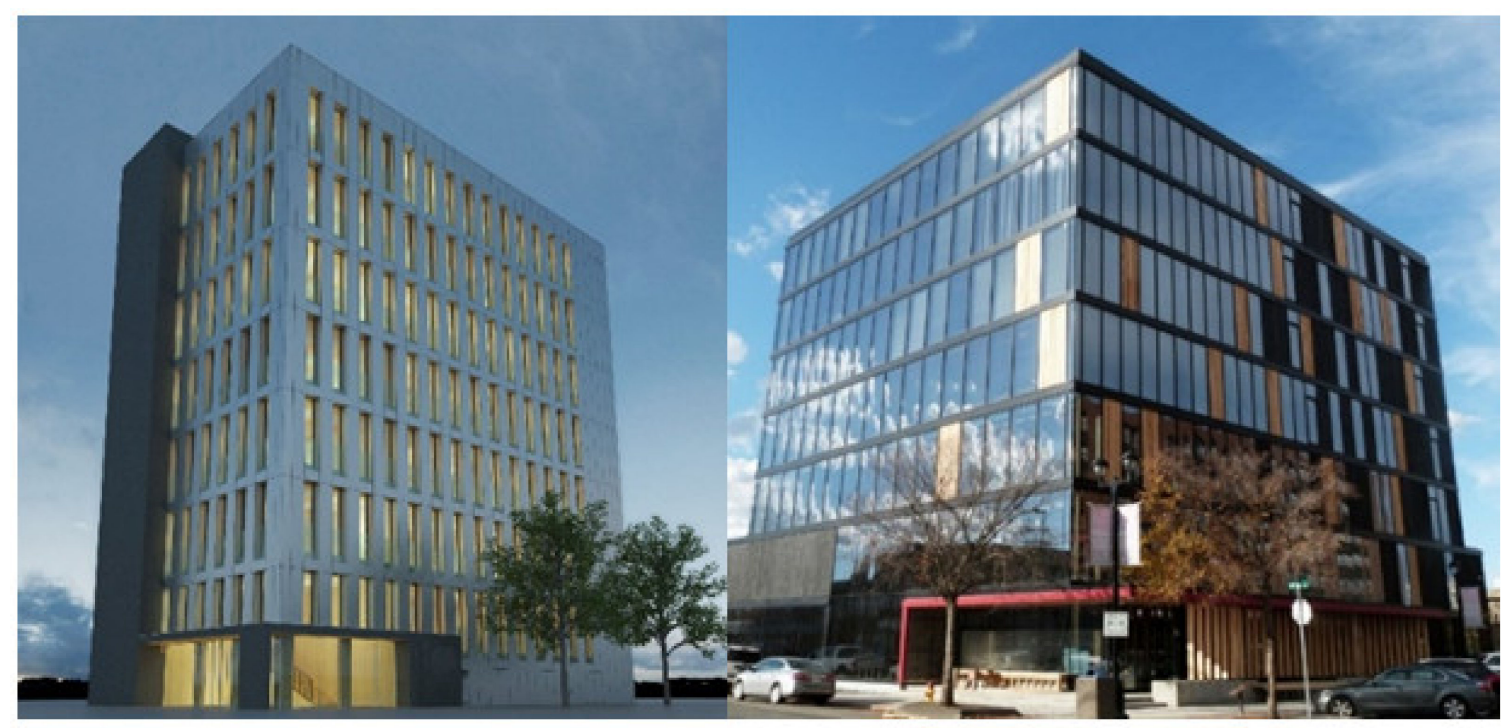

(a)

(b)

Figure 6. LCT ONE, Austria (a) and Wood Innovation Design Centre, Canada (b) (Photo in public domain). 


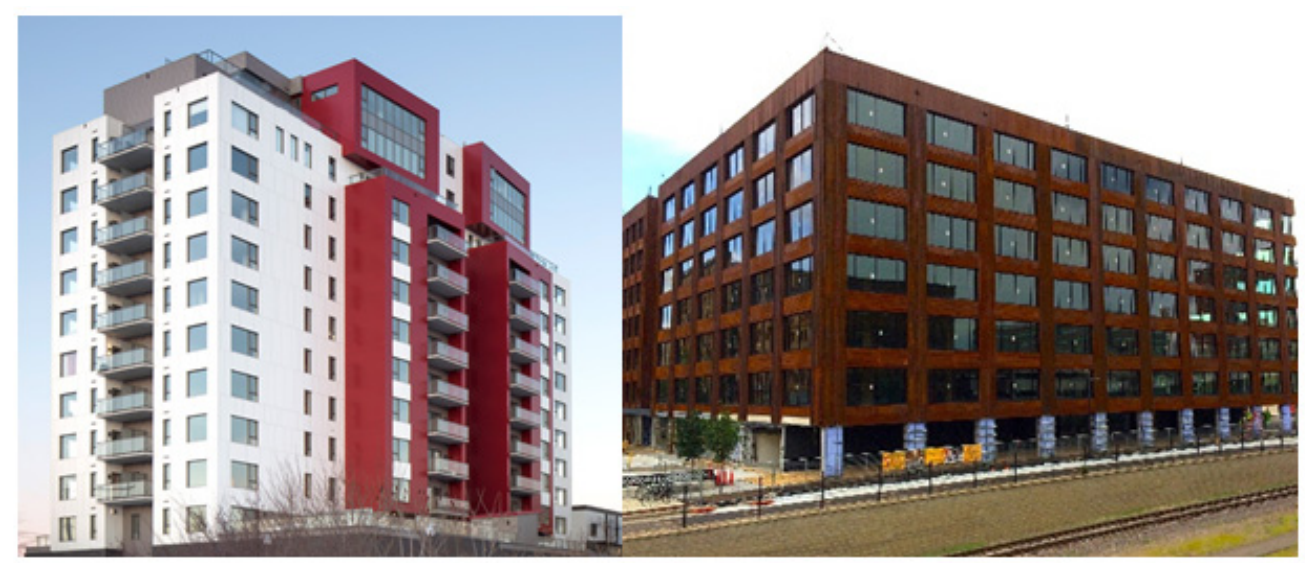

(a)

(b)

Figure 7. Origine, Quebec (a) and T3 Minneapolis (b) (Photo in public domain).

\section{Tall Wood Initiatives}

Traditional light-frame wood buildings in some countries were restricted in the past to four or five stories in height in most jurisdictions due to fire safety concerns. In Canada, for example, there are nearly 200 buildings made of industrial old brick and timber up to 8 stories, about $30 \mathrm{~m}$ in height, built before 1940 . The construction of such buildings has been prohibited in later decades mainly due to the introduction of combustible vs. non-combustible construction concepts and limits on wooden building height introduced in NBCC in 1941 [4].

\section{Research and Development of Wood Products and Systems}

Over the last two decades, there has been significant progress in technology associated with new wood products and systems, particularly in North America and Europe and regions around the Pacific. New products such as Cross-Laminated Timber have been developed in Europe. At the same time, the adoption of numerical control and automation have significantly enhanced production quality and efficiency for rapidly expanding markets in Europe, North America, Australasia, and East Asia. North America is leading in the promotion of new products and systems through an increased number of applications facilitated by updated codes and regulations. Natural Resources Canada (NRCan) and the National Research Council Canada (NRC) have made significant investments through supporting research activities addressing those issues to expand the use of wood in mid-tohigh-rise construction and facilitate code changes in Canada (Jones 2014). Examples of the initiatives are the Network on Engineered Wood-based Building Systems (NEWBuildS) and the Mid-rise Wood Building project.

NEWBuildS was a multi-disciplinary Canadian National Science and Engineering Research Council (NSERC) project. The goal of NEWBuildS was to advance scientific knowledge and construction technologies that enabled wood-based products to be used in mid-rise and non-residential construction or integrated into hybridized construction. The research program of NEWBuildS was established in collaboration with FPInnovations, the wood industry and design community, and was organized into four linked research themes. A key technical outcome of the network research was the development of new, and the improvement of existing, technical tools for use by design engineers, researchers, and product manufacturers to predict product and building system performances. These technical tools included sophisticated mathematical models based on first principles, applied engineering models, process models, and experimental techniques.

\section{Cross-Laminated Timber}

Cross-Laminated Timber (CLT) is a type of engineered wood product developed in central Europe in the early 1990s and has been used in building applications around 
the world but predominantly in Europe over the past two decades. It uses dimensioned glue laminated timber, with lamination layers oriented orthogonally. CLT panels can be manufactured into long panels with the width limited only by that of the press. The panels can be pre-cut and pre-grooved into desirable shapes, shipped to the construction site, and erected quickly. CLT behaves almost like solid wood in load bearing, and thus CLT walls are very efficient in resisting gravity loads. In recent years, CLT has become an emerging product for multi-storied timber buildings.

Soon after its introduction to the market in Europe, CLT attracted considerable interests in other regions. In addition to significant initiatives in North America, countries such as Japan, Australia, New Zealand, and Chile invested in the development of their own products using available species suitable for applications in local environments. The industry initiatives were complimented by government supports and updates in codes and standards to allow new products into the market while ensuring quality through necessary regulations.

CLT systems are considered well-suited for timber buildings more than five stories tall due to their strength and the potential to achieve the required fire rating [5]. Not surprisingly, there has been a worldwide growing trend of constructing tall CLT buildings, as confirmed by the recent Forestry Innovation Investment and Binational Softwood Lumber Council survey of international tall wood buildings [6]. Eight out of the ten buildings surveyed, from five to ten stories in height, utilized CLT as either the main lateral system or as floor panels.

Based on a preliminary study [7], the cost of including CLT in the design can be comparable to reinforced concrete for buildings with 8 to 14 stories in the Pacific Northwest of USA. In a recent survey [8], the lack of adequate knowledge has been identified as the primary barrier for use of CLT in high-rises. To assist with that effort, the "Technical Guide for the Design \& Construction of Tall Wood Buildings in Canada" was published by FPInnovations in 2014 with financial support from NRCan [2]. It has been prepared by a group of more than 85 experts from Canada, the USA, and other countries. The guide is designed to assist designers, code consultants, developers, building owners, and authorities in understanding the key technical issues and challenges associated with the design and construction of tall wood buildings. It has been prepared to be consistent with the design objectives in 2010 NBCC, the latest published edition at that time. The guide invokes the conceptual design process and how it is applied to tall wood buildings to instigate thoughts on the building systems through principles and potential solutions. The issues with code compliance following the "alternative solutions" path are discussed. It also includes information to assist the consenting authorities in establishing a process to evaluate a scheme designed following that approach.

Different wood-based structural systems such as platform type, post-and-beam with wood-frame infill, mass timber, and associated wall assemblies are presented in the guide. Recommendations are provided for the analysis and testing of structural systems for wind and seismic loading to meet the structural design requirements and additional serviceability criteria such as sound insulation and floor vibration control. Details such as design considerations and input parameters for connections and assemblies are also covered. Best practices and standards for prefabrication and inspection of the building assemblies are included. It also covers quality assurance issues associated with personnel, execution and record keeping.

Proper connection between panels is an essential element for achieving the desired performance of CLT structures. Since the inception of the material, significant efforts have been devoted to developing different connection types. Most of the connection details suggested for North America have been adopted from the research performed in Europe during the last two decades [9]. However, some innovative connection types have been investigated to allow quick assembly and replacement taking advantage of the prefabrication facility. Other aspects of structural design, e.g., deflection due to short-term loading, creep, and long-term performance, have been outlined in the CLT Handbooks. 
They also suggest requirements for satisfactory vibration and acoustic performance and the means to achieve them. Building enclosure designs for necessary hygrothermal standards and construction procedures are also covered.

Design considerations for the building enclosure to achieve durability of wooded buildings are mentioned. Information is provided on heat transfer and the movement of air and moisture through the building enclosure and within a building. Guidance is also provided on building performance testing by short- and long-term measurements, the monitoring of parameters such as airtightness, vibration, sound insulation, floor and building vibrations, energy efficiency, etc., and the necessary building maintenance. Some regions in North America likely to have tall CLT buildings (e.g., the West Coast of the USA and Canada) have significant seismic risk. Developing solutions for designing tall CLT buildings in seismic regions, therefore, has become a priority for researchers and engineers.

In addition to the development of the physical building system, a shift towards performance-based seismic design philosophy must also be made for the new tall CLT buildings in order to address the evolving needs of the future urban communities. Similar to existing concrete and steel structures, tall CLT buildings will be expected to perform at the current code level or better. It is also desirable for the proposed tall CLT buildings to achieve resilience against major earthquake events with minor and easily repairable damage.

Extensive research on CLT for application in multi-storied construction started in Europe after the early 2000s with a significant increase in construction, including buildings above five stories. However, the understanding of panelised CLT in lateral force resisting systems was still limited, particularly for the Western USA and Canada, which are high seismic regions. In order to address moderate seismicity in the province of British Columbia in Canada, FPInnovations (FPI) initiated a series of research projects on seismic design of CLT systems. Popovski et al. [10] conducted CLT wall tests on 32 shear walls with different aspect ratios, openings, and panel combinations, which identified the inter-panel joints and metal brackets as the main source of ductility in CLT walls for building in seismic regions. Following these tests, Popovski et al. also made the first attempt to estimate the seismic modification factors (R-factors) for a CLT system in NBCC [10]. A summary on the seismic performance and seismic design of CLT structures is part of the FPInnovations' CLT Design Handbook [9].

With knowledge gathered from within North America and Europe, FPInnovations published the CLT Handbook Canadian edition (Gagnon and Pirvu 2011), which was instrumental in the design and construction of the first CLT projects in North America. The U.S. edition of the CLT handbook was published through a collaborative effort of FPInnovations Canada, the American Wood Council, the United States Forest Products Laboratory, the Engineered Wood Association (APA), and Woodworks U.S., with funding from the Binational Softwood Council, the Forest Product Laboratory, the British Columbia Forestry Innovation Investment (BCFII), and three CLT manufacturers. The handbook covers a wide range of subjects such as CLT manufacturing, construction, fire, and acoustic performance in addition to structural design approaches and lateral load systems design.

Extensive studies to determine seismic design factors for a particular CLT building configuration for both the USA and Canada in accordance with the two codes (ASCE-7 and NBCC, respectively) was undertaken by Pei et al. [9,11]. Another robust approach for a range of building configurations has been undertaken at Colorado State University (ASCE 2010), with support from the U.S. Department of Agriculture, to identify seismic performance factors for CLT shear walls for the Federal Emergency Management Agency P-695 methodology in ASCE-7 [12].

The United States National Science Foundation funded the NEES-CLT (USDA 2014) research project that focused on developing seismically resilient solutions for CLT systems for tall buildings in the United States with the intention to propose a road map for developing CLT tall buildings in the United States, with the first targeted construction in 2020. It was noticed that the societal needs and expectations for tall CLT buildings in seismic regions are not yet well defined, and this was also investigated as part of the NEES-CLT project. 
The potential market was identified as 8- to 20-story buildings in urban environments. The study found that savings in repetitive architectural patterns, fast modular construction, and the potential to save on lifecycle operational costs and resiliency during earthquakes are taken into consideration for the cost effectiveness of design options. However, the direct cost of the CLT option was still the main factor influencing the decision on material in most projects and the CLT option had to be of comparable cost while sustaining or exceeding the functionality of its competitors to capture significant market share. Firerelated code provisions, lack of experience, and innovation and research funding were identified as additional challenges for introducing CLT construction in the United States. The recommendations of the project suggested that the parties interested in tall CLT buildings work on manufacturing, code compliance for fire safety, education, and outreach. The CLT industry was also encouraged to work with the steel and concrete industries to develop hybrid structures that include CLT components.

Similar to building systems with other materials, a series of tiered objectives was proposed as performance expectations for tall CLT buildings [11]. Complying with current code requirements was the basic performance objective for the new tall CLT systems. Betterthan-code performance was the next level to be offered to the stakeholders. Structural systems providing seismic resilience were expected to perform at the highest performance level achievable. Performances during an earthquake and advantages such as reduced damage and down time afterwards demonstrate the relative efficiency of such systems and can also improve public perception and willingness to implement. The engineering parameters were dictated by application of performance-based seismic design philosophy. Construction of a 12-story CLT building in the Pacific Northwest by 2020 (termed "Vision CLT2020") has been set as the goal for the project [13]. That is expected to be a milestone in building tall CLT structures in the USA, paving the way for many others of the type all over the country. (Figure 8).

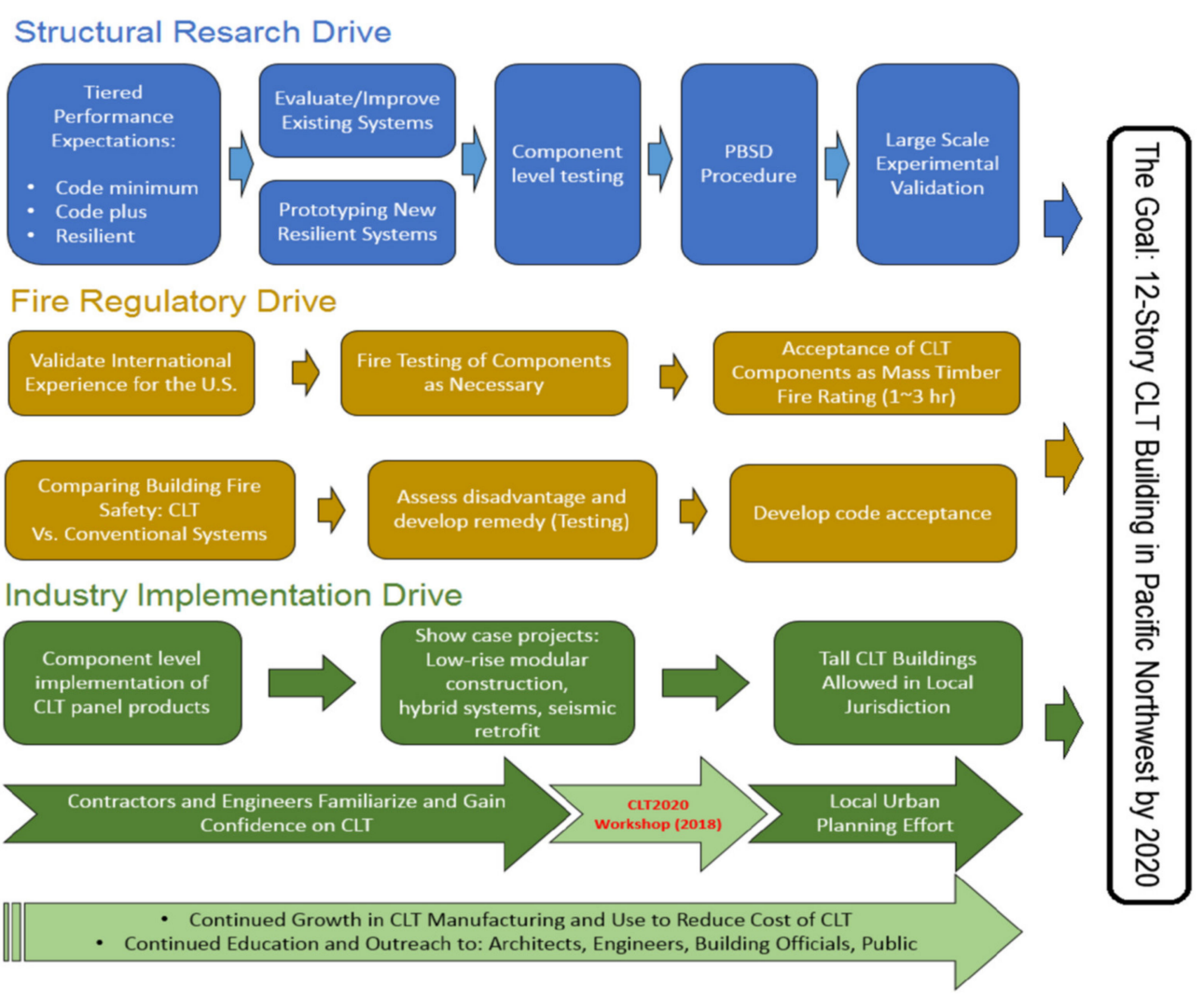

Figure 8. Roadmap for tall CLT buildings in the USA (Source: NEHRI Tall Wood, http:/ / neesclt. mines.edu/index.html, accessed on 5 September 2021). 
To promote the cause further through design and construction of the first examples, the Canadian authorities launched the tall wood building design competition. In 2013, the Canadian Wood Council issued a request for Expressions of Interest for design teams to use innovative design and build high-rise wood demonstration projects. Under funding from Natural Resources Canada (NRCan), this initiative links scientific advances with technical expertise to showcase the benefits of innovative wood-based structural solutions. To support the initiative, a Technical Guide for the Design and Construction of Tall Buildings in Canada was developed by FPInnovations.

Submissions were reviewed by an Evaluation Team, and the three selected projects were: Cathedral Hill2, a Condominium plus Office building in Ottawa which comprises housing with 12-stories and a floor area of $11,750 \mathrm{~m}^{2}$; Origine, an 11-story Condominium (Apartments) in Quebec City with a floor area of $11,120 \mathrm{~m}^{2}$; and an 18-story Student Residence within the University of British Columbia campus in Vancouver with a 15,400 $\mathrm{m}^{2}$ floor area. The different systems being considered include the post-tensioning system from New Zealand, CLT/Glulam wood systems, and Hybrid wood systems. The UBC building is a hybrid structure with a concrete core. Each project was divided into six key elements/phases: schematic design, design development, and construction documents; research, testing, and additional support; building system code acceptance; cost analysis and approvals; construction; post-construction; and communications and training. Incremental funds will be allocated to each step at appropriate times. There were challenges involved in mitigating/sharing risks, additional issues/considerations needed on managing intellectual properties, and code acceptance. The engagement and education of stakeholders was found to be a key to broader future commercialization. It was also suggested that a common research and development plan/matrix applicable to each project is to be developed with design development milestones established and monitored for each proponent group [4].

In 2014, the United States Department of Agriculture, in partnership with the Softwood Lumber Board and the Binational Softwood Lumber Council, announced the U.S. Tall Wood Building Prize Competition [14]. This competitive prize, open to teams of architects, engineers, and developers, is expected to showcase the architectural and commercial viability of advanced wood products such as Cross Laminated Timber (CLT) in tall buildings. The United States Federal Register announced that "the selected proponent(s) will be the team demonstrating the best ability to utilize new scientific data, to develop technical expertise, and to use incremental funding to safely design, specify, and construct a building of a minimum of $80 \mathrm{ft}(25 \mathrm{~m})$ in height (not including a reinforced concrete podium) in the United States of America that can showcase the application, practicality, and sustainability of innovative wood-based structural building solutions in tall building construction".

The results of the competition were announced in 2015. The 2 winners were a 12-storied, mixed-use Framework building in Portland, Oregon and a 10-storied condominium at 475 West 18th in New York City. The winners received support for incremental costs of pioneering wood construction techniques to address the engineering design and code variances needed to incorporate wood technologies into new building sites. The competition required that the winning project team source a share of materials from rural, domestic manufacturers and domestic, sustainably managed forests in order to jumpstart new production and economic opportunities in rural America. The Framework project is going ahead into implementation. Additional research and testing are currently underway; construction is set to start shortly afterwards $[15,16]$.

\section{Structural Systems for Tall Wood and Hybrid Buildings}

Braced frames, with additional members connecting joints and/or other members, have enhanced ability to resist gravity and lateral loads. In typical braced frames, the braces are subjected to axial forces only and they help load-bearing capacity of the frames considerably. The addition of braces also resulted in a significant increase in the overall stiffness of the system, hence reducing deflection to satisfy permissible drift limit requirements. Bracing systems have been in use in mid-to-high-rise wood buildings for a long time. Their 
applications have grown noticeably in recent years with the availability of high-strength engineered wood products, innovative details, and advanced manufacturing/production capability. Two notable practical examples are shown here.

First, the 14-story "Treet" Apartment building in Bergen, Norway (Figure 9) was the tallest wood building in the world when it was completed in 2015 [17,18]. The building has a number of innovative features developed through research for particular application in this building, and the completed building demonstrates the feasibility of those in a practical building of that height range. There are load-carrying glulam trusses and two intermediate strengthened levels to support prefabricated building modules above a concrete garage. The structure also includes innovative glulam-braced frames as part of a lateral force resisting system designed primarily for wind loads. CLT panels are used in the elevator shaft and interior walls, but the main load bearing system does not rely on their contribution.

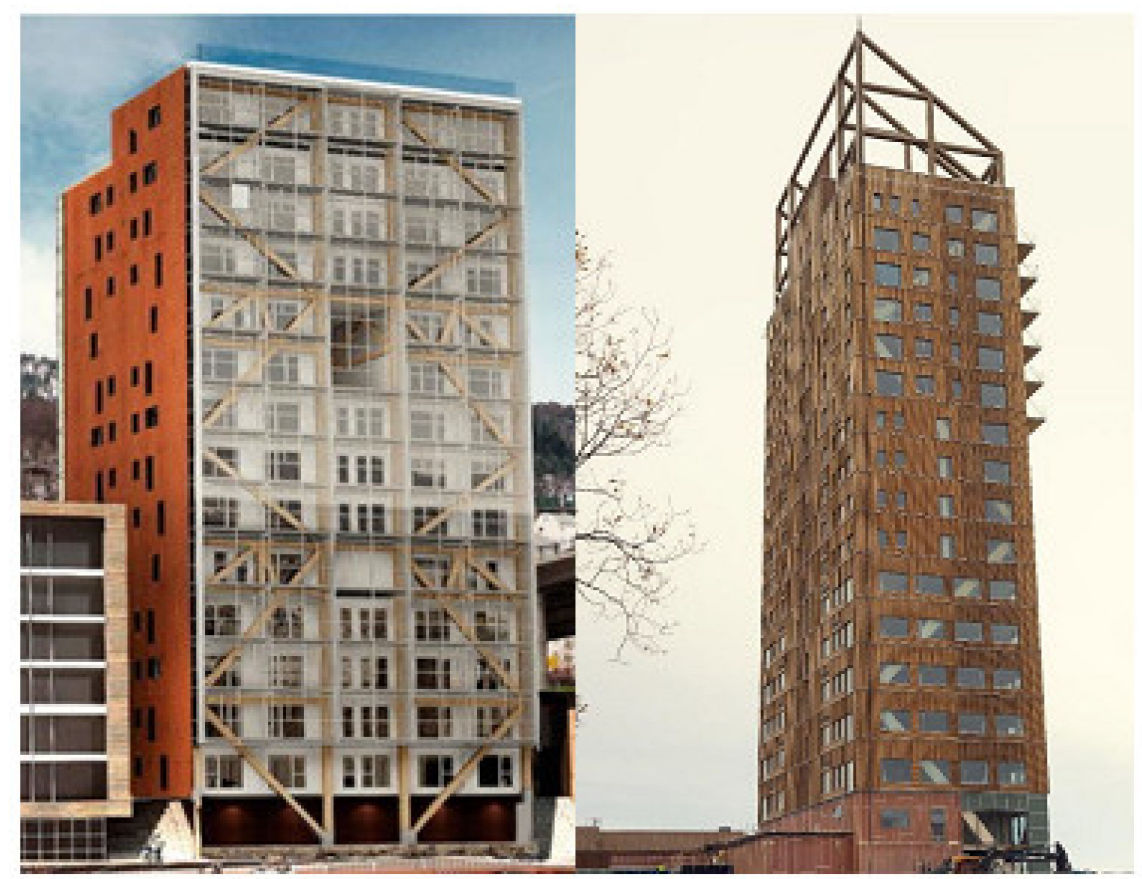

(a)

(b)

Figure 9. Treet, Bergen (a) and Mjøstårnet, (b) (Photo in public domain).

The MjØstånet in Brumunddal, Norway (Figure 9) was designed by the same group involved with the Treet building, and experiences from there were used in the design of a similar structural system. However, it is about $30 \mathrm{~m}$ taller than Treet with a similar glulam structure, without building modules. Planning for the building started in early 2015, and it was completed in March 2019. The 81-m-tall building has 18 floors and uses glulam frames with diagonal braces for gravity and lateral loads, predominantly due to wind. The floors of the first 10 floors are wooden, and the rest are of concrete for improved serviceability performance. The expected peak accelerations were just above the code limit for the top floor but deemed acceptable by the client. All the structural members were prefabricated, and construction was quick, even for members with considerable dimensions. The large glulam cross-sections provided additional fire safety. The structure has to protect against moisture, and prefabricated façade wooden panels are used in the building envelope. Material use for the building is optimized to keep cost of structure competitive.

The Hoho Tower in Vienna, Austria (Figure 10) is currently the tallest wood building in the world. The 84-m-tall building with 24-stories was completed in 2019. It has concrete cores and spandrel beams; the rest of the structure is made of wood. CLT panels were used as floor diaphragms and exterior walls. 


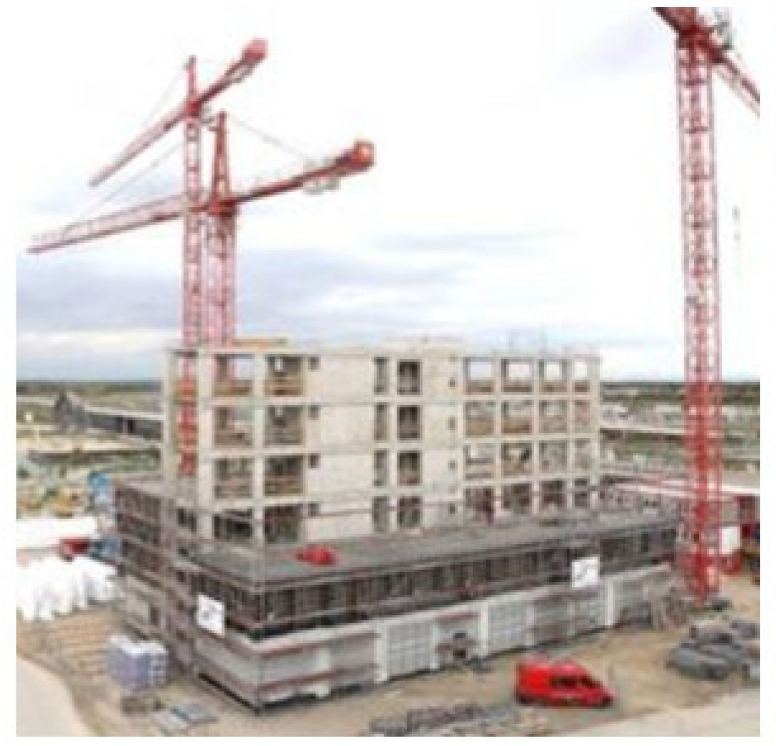

(a)

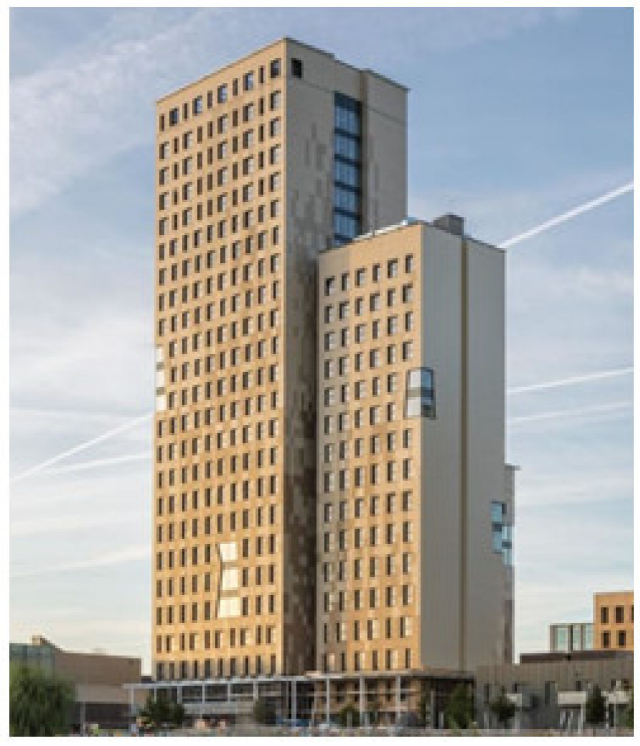

(b)

Figure 10. HoHo Tower, Vienna, Austria during construction (a) and completed (b) (Photo in public domain).

Additional concepts have been proposed by some other practitioners. Michael Green Architects (MGA), in association with Equilibrium Consultants, both from Vancouver, has designed buildings up to 30-stories tall following the "Finding Forest Through Trees (FFTT)" concept (Figure 11). There has been additional research on the structural system [19]. Chicago-based consulting company Skidmore Owings and Merrill (SOM) has prepared a virtual timber design of a 42-story concrete building built in the 1960s. The design includes CLT floors and framing in combination with concrete (Figure 12).

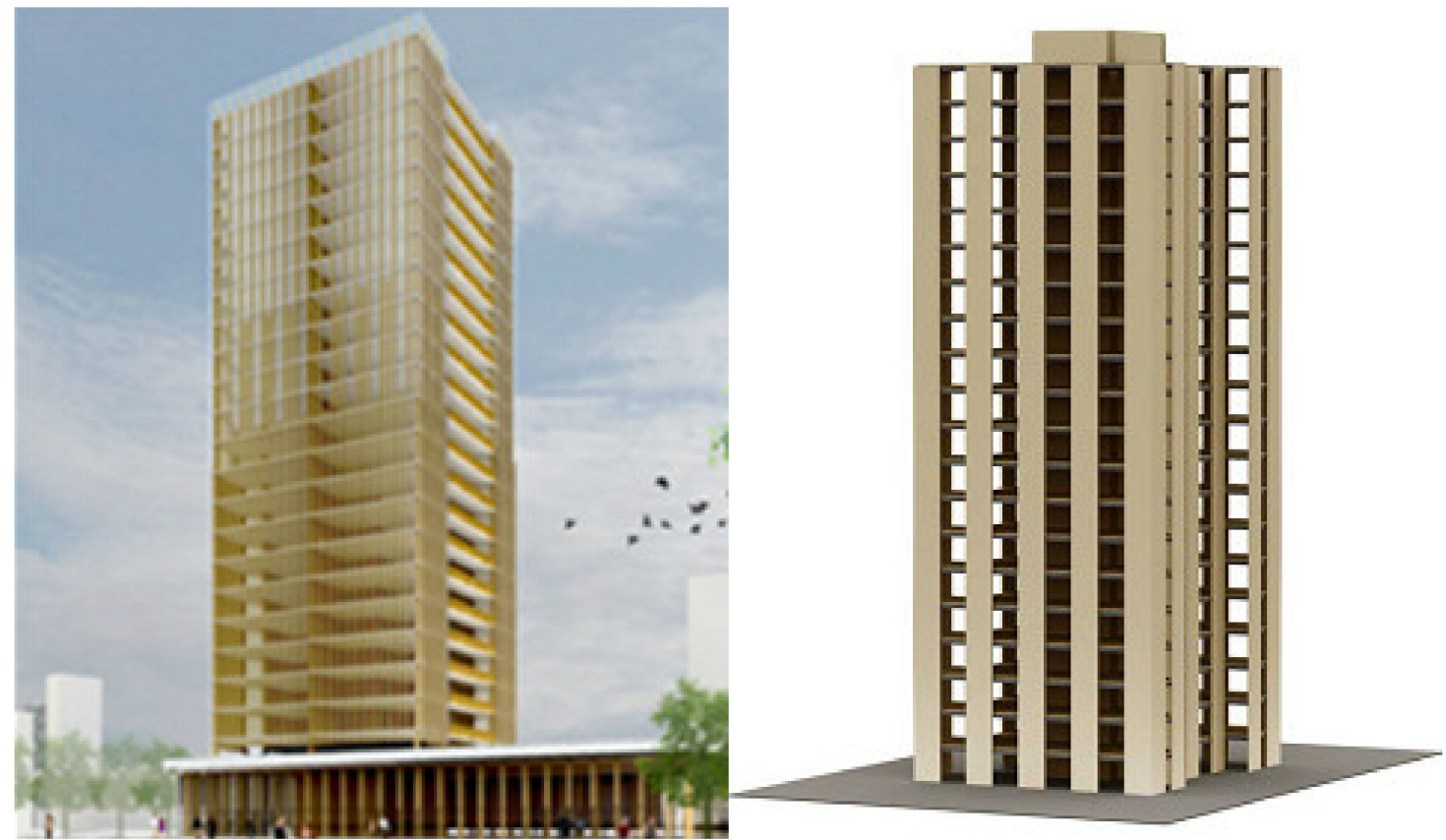

Figure 11. FFTT Structure (Green and Karsh, 2012). 


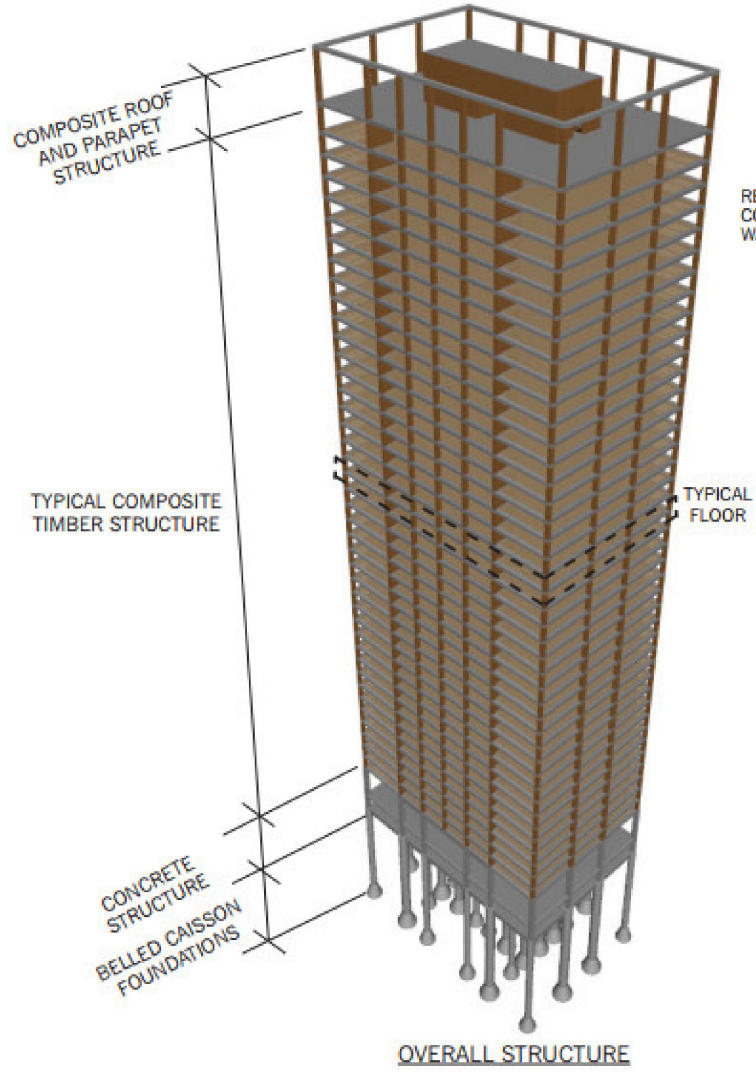

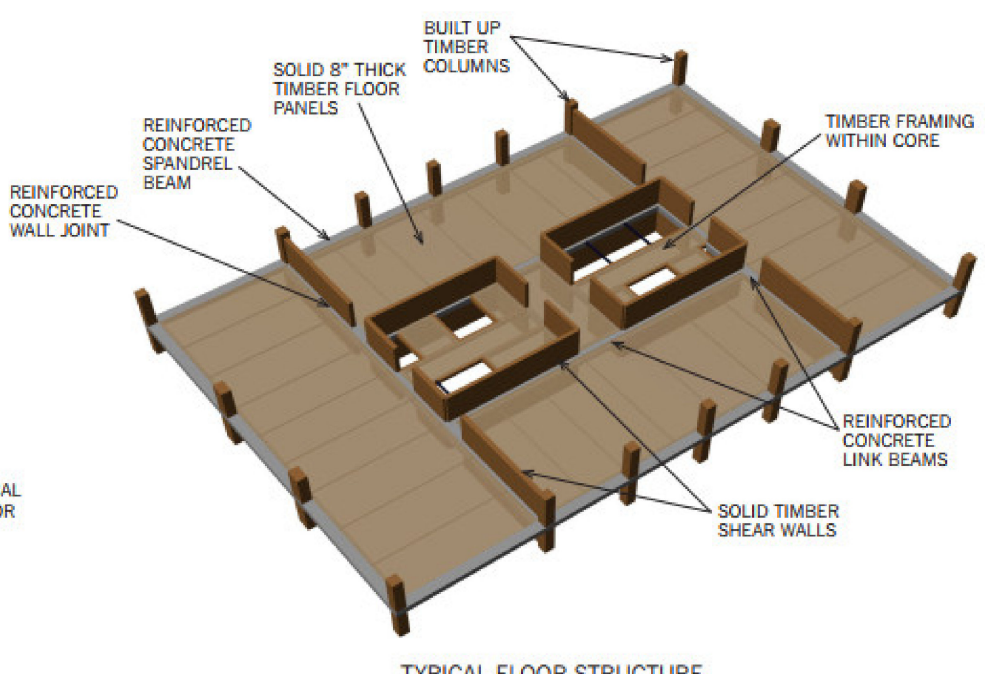

TYPICAL FLOOR STRUCTURE
ESTIMATED QUANTITIES

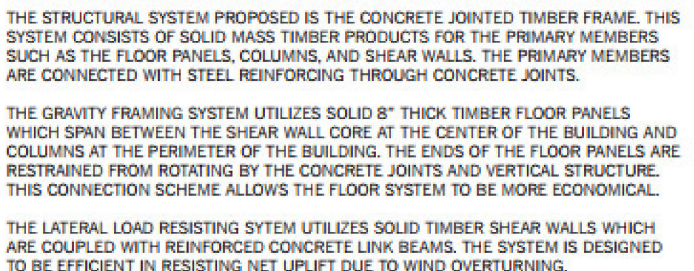

SUB AND SUPERSTRUCTURE: TIMBER: 0.80 cu.ft/st CONCRETE: 0.25 cu.tt/st REINFORCEMENT: $1.7 \mathrm{pst}$ FOUNDATIONS: CONCRETE: $0.09 \mathrm{cu} . \mathrm{ft} / \mathrm{st}$ CONCRETE: $0.09 \mathrm{cu} . \mathrm{ft} / \mathrm{st}$
REINFORCEMENT: $0.1 \mathrm{pst}$

Figure 12. SOM Timber Tower details (SOM, 2013).

In light of the lessons learned from damages to structures and consequent financial losses in recent earthquakes in countries such as New Zealand, Chile, and Japan, there is increasing interest in more realistic Resilient-based approach to estimate and minimize damage, downtime, and losses from an earthquake. The ARUP has proposed the outline of Resilient Based Design Initiative [20] for buildings. It takes into account the statistical nature of damages to develop fragility curves for to building structures and components. It provides guidance for calculating costs of functional recovery to highlight motivation for adopting the approach.

\section{Effects of Wood Properties on Applicability}

Extensive research has been performed to study the effects of wood properties for applicability in tall buildings. Among different aspects, physical (load bearing capacity and creep behavior) and hygrothermal (heat and moisture propagation) properties are of particular interest [21]. The moisture content migrations in CLT panels, the modeling of creep behavior of axially loaded CLT panels, and compression tests of CLT materials at different moisture contents have been studied to see the effects of moisture content in CLT to its strength and elastic modulus. The results from experimental studies showed decreases in moisture content absorption coefficients in CLT with increases in the relative humidity. The coefficients are about four to five times higher than those in solid wood of the same species due to the gaps among lumbers in CLT. A loss of tendon force in CLT panels over long period of time was also observed to examine reliability of estimates. Test data and numerical models showed noticeable levels of creep in the material over a period of nine months. As the case with other wood structures, the careful arrangement of cladding and weather tightness is essential for tall wood buildings. The creep and time-dependent effects are also to be taken into account during planning and design to avoid any potential issue with long-term performance of this type of buildings. 


\section{Tall Wood and Hybrid Buildings in Seismic Regions}

The systems commonly used in tall wood buildings are generally applicable in structures in seismic regions with appropriate provisions for necessary lateral load resistance capacities. That often means added members or components compared to non-seismic solutions. Each of the four buildings of Canny di Cambiamento in Milan relies on continuous solid walls made of CLT panels (Figure 13).

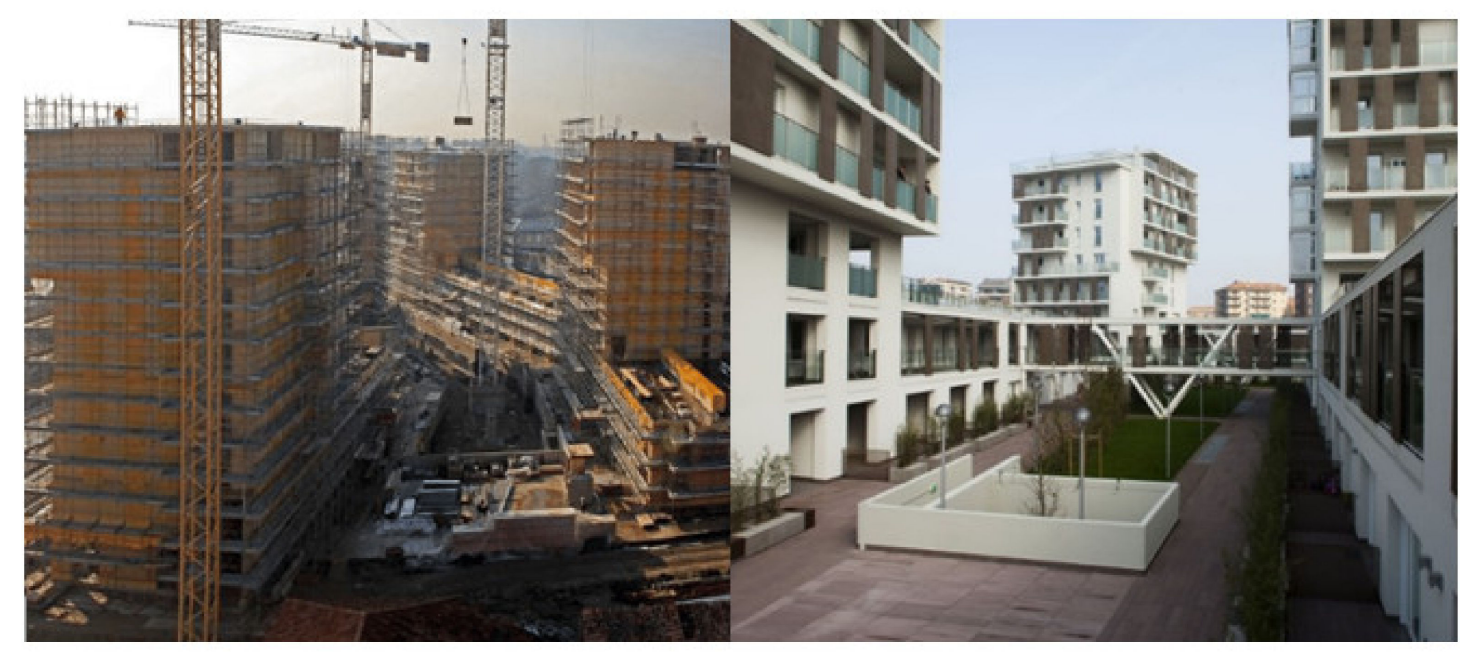

(a)

(b)

Figure 13. Cenni di Cambiamento during construction (a) and after completion (b) (Photo in public domain).

The Earth Sciences Building (Figure 14) of the University of British Columbia, Vancouver houses research and teaching areas for Earth and Planetary Sciences since its completion in 2012. The North Wing of the building includes glulam frames with chevron braces along the short direction (Figure 14). The building frames are made of glulam combined with LVL composite floor.

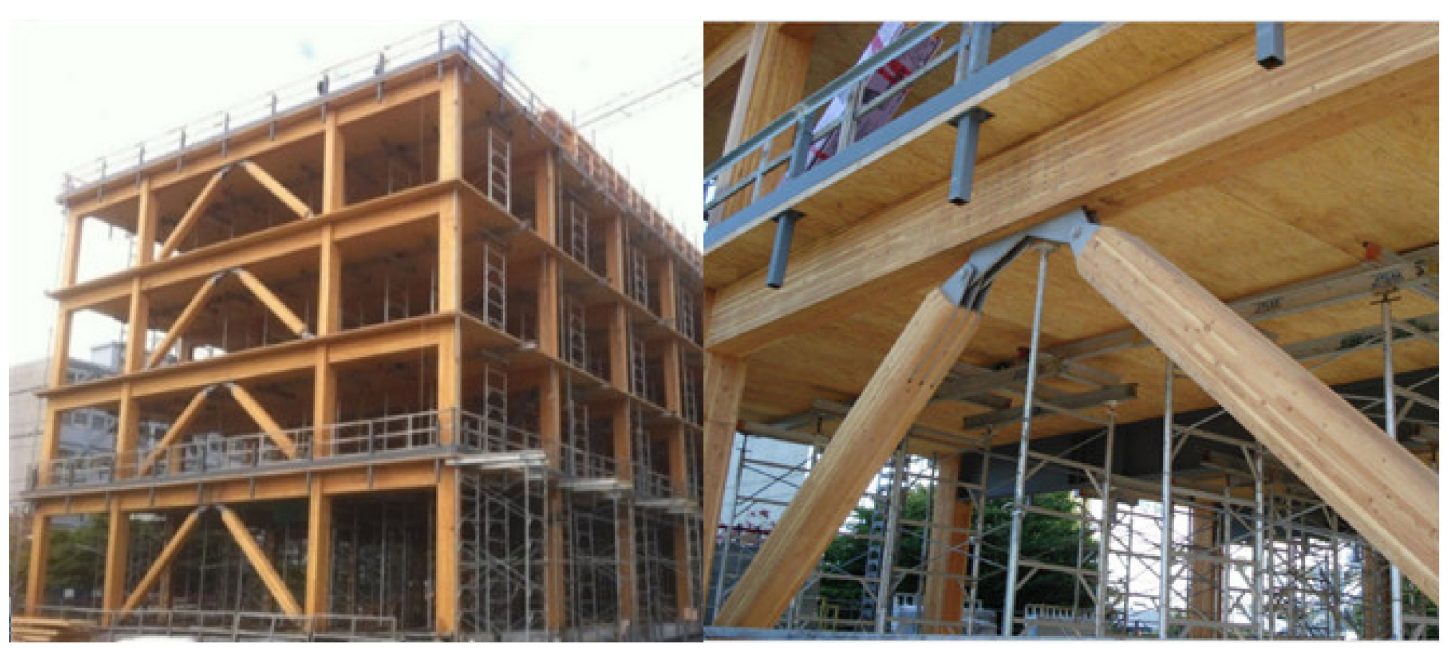

Figure 14. UBC Earth Science Building, Vancouver, Canada (Photo in public domain).

Braced frames' ability to resist lateral load is often limited by the capacity of individual braces. To increase load-carrying capacity, particularly under compression load, bucklingresistant braces have been proposed [22,23]. Special materials and careful preparation are required for the assembly of the steel-timber composite braces. 


\section{Connections and Ductility}

Moment connections with epoxied threaded rods embedded inside glulam beamcolumn joints (Figure 15) were proposed and tested in New Zealand in the early 1990s. The results showed significant ductility in the connections achieved through the yielding of the materials. A similar arrangement with the addition of unbonded post-tensioning (Figure 15) was developed at the University of Canterbury, Christchurch in the mid-2000s. Ductility is achieved mostly through the yielding of internal or external mild steel energy dissipators (Figure 16) during the rocking motion of the connections when subjected to lateral loads. Post-tensioning provides a re-centering ability to the connection in addition to contributions in moment capacity.

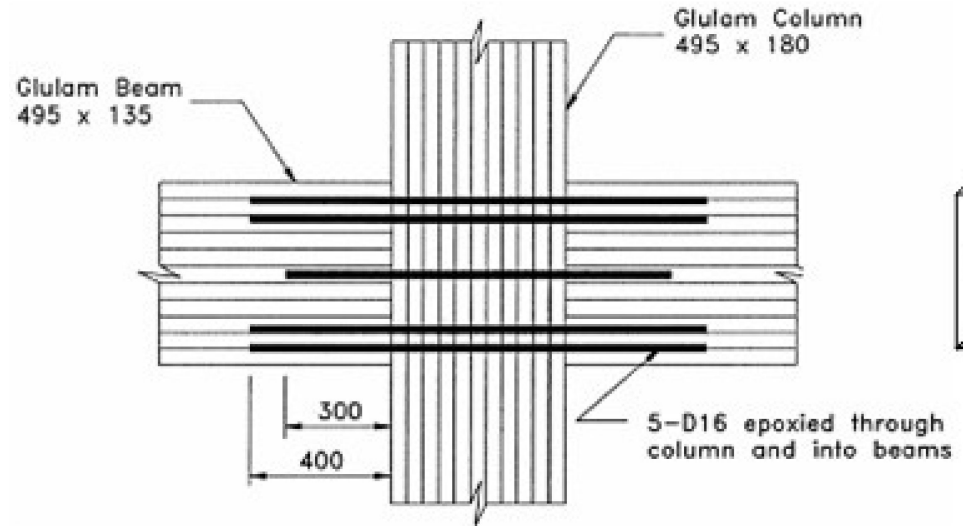

(a)

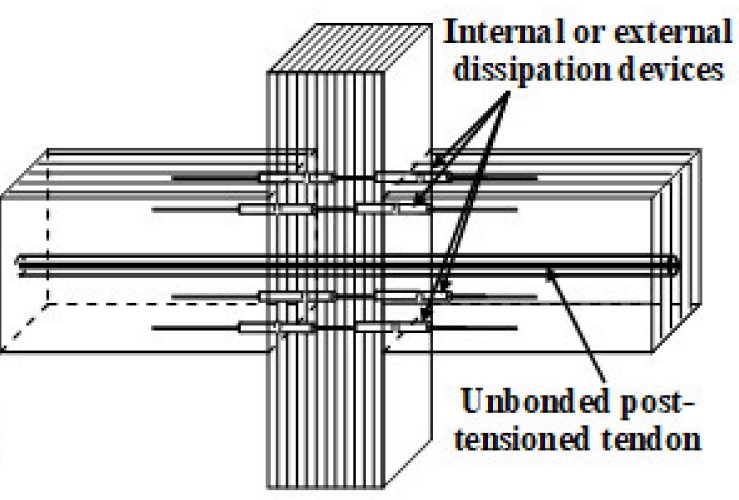

(b)

Figure 15. Connection with epoxied rods (a) and post-tensioning (b).

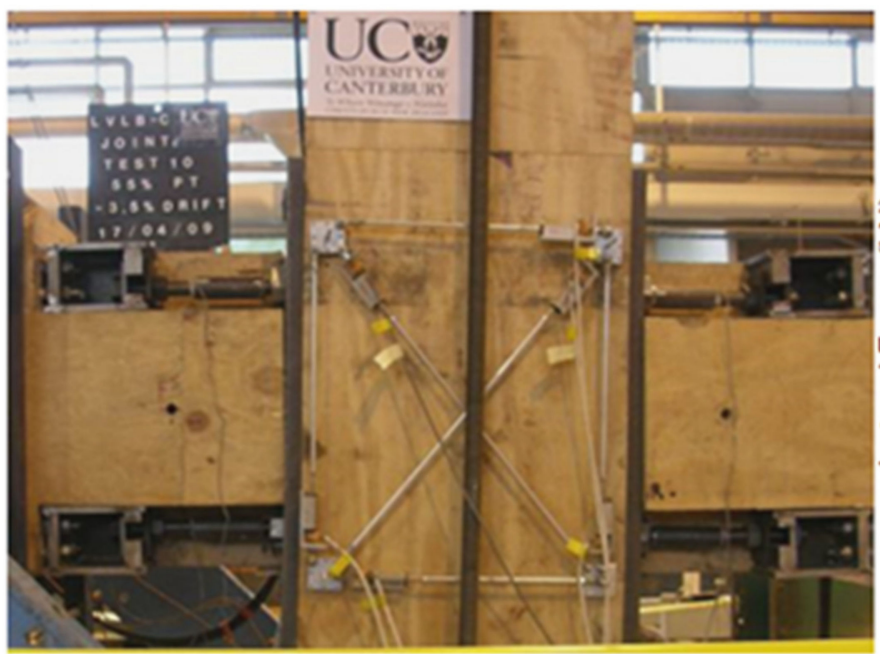

(a)

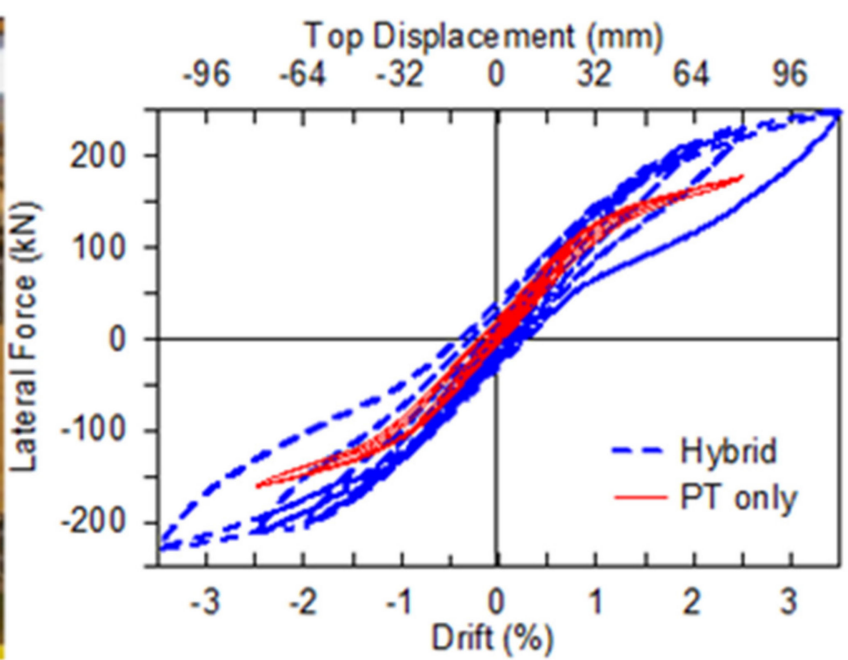

(b)

Figure 16. Post-tensioned joint (a) and load-displacement (b).

The concept is not limited to beam-column joints only; it is applicable to similar connections and members in general. Other types of energy-dissipating elements, also made of mild steel, have been used in different connections and systems. One of those includes U-shaped Flexural Plates (UFP) in vertical plane between adjacent shear wall panels (Figure 17). As the panel resists in-plane lateral loads, there is relative displacement between the two ends and energy is dissipated due of yielding of the plates [24]. It is to be noted that the UFPs show uniform and stable hysteretic behavior under repeated loading in alternating directions. Similar to beam-column joints, post-tensioned shear walls with UFPs (Figure 18) exhibit a self-centering ability in addition to significant energy dissipation. 


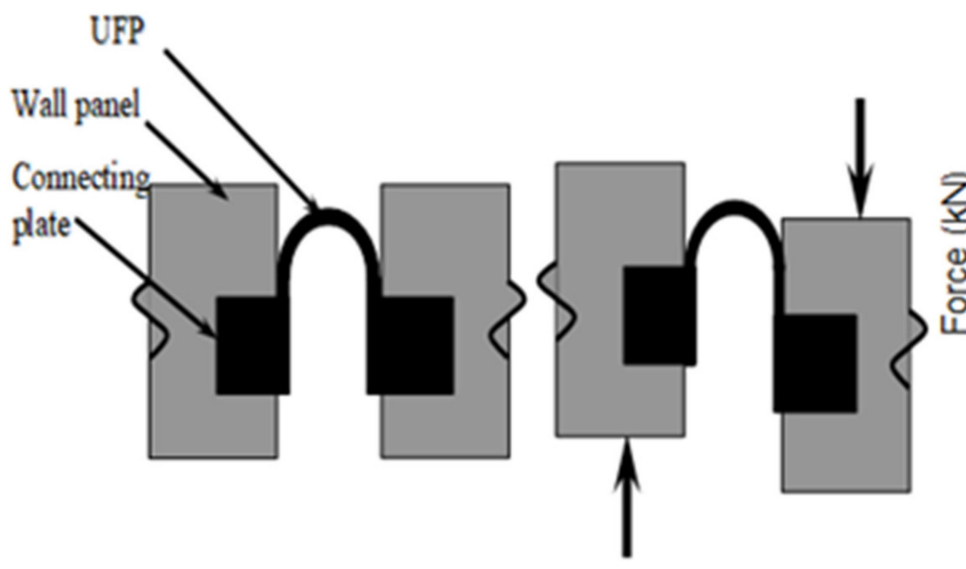

(a)

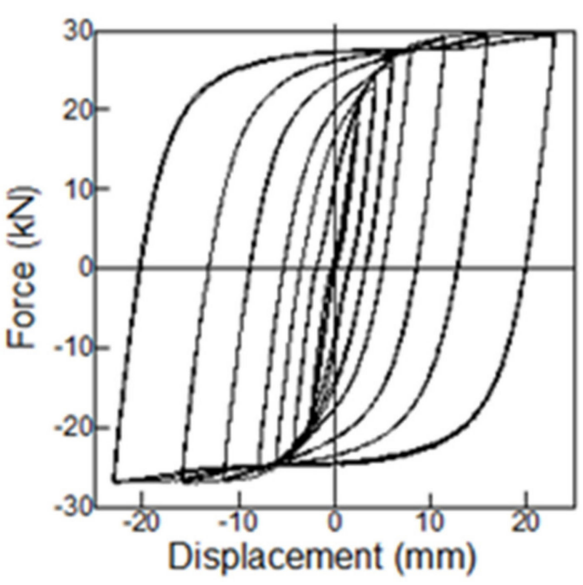

(b)

Figure 17. U-shaped flexural plates (a) and load-displacement (b).

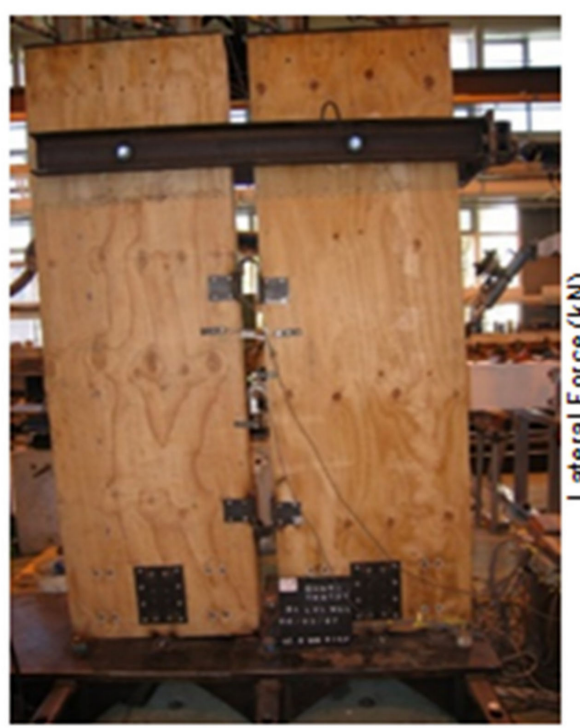

(a)

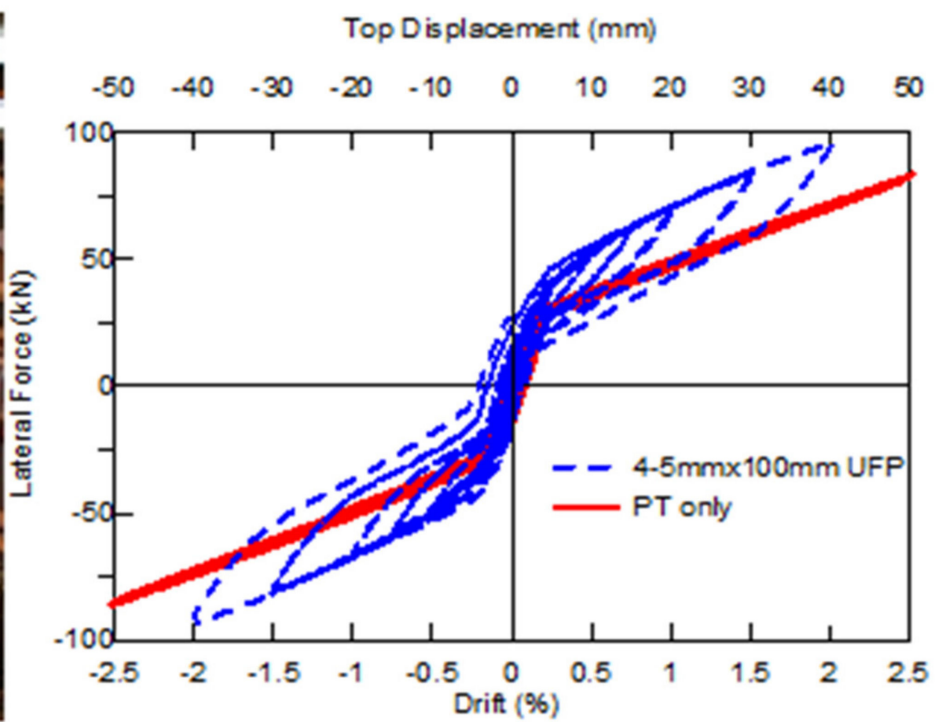

(b)

Figure 18. Rocking walls coupled with UFP (a) and force-displacement of walls (b).

Connections are critical in Capacity Design and the criteria for connection design is derived directly from the implementation of design principles of structural members [25]. Typical timber structures with metal connection elements are ideally suitable for adoption of Capacity Design Principle, with careful detailing and arrangements. To activate the desired load transfer mechanism, connection elements have to be engaged at the same time with structural members. Lowest value of the force capacity of all the members within the hierarchy would the upper limit for connection elements. That means the connection element will yield before elastic limits of the members are exceeded. At the same time, they have to provide necessary redundancies against overall instability or collapse of the structure. Since almost all connection elements are made of metal, they are good sources of energy dissipation and they are capable of undergoing significant deformation before failure. As an additional advantage, compared to the structural members it is generally much easier and cheaper to replace connection elements after major deformation/damage takes place during an extreme event. 


\section{Case Study I: UBC Brock Commons with CLT Cores}

The Brock Commons at the University of British Columbia (Figure 19) is an 18-story student residence and currently the tallest wooden building in North America. The hybrid structure has the first story and the two cores built with concrete, and the rest is of wood. The columns carry gravity load only while the CLT floor diaphragms transfer all the lateral loads to the cores. An exercise for alternative solutions concluded that it is possible to replace the existing cores with timber cores made of CLT panels and additional shear walls $[26,27]$.

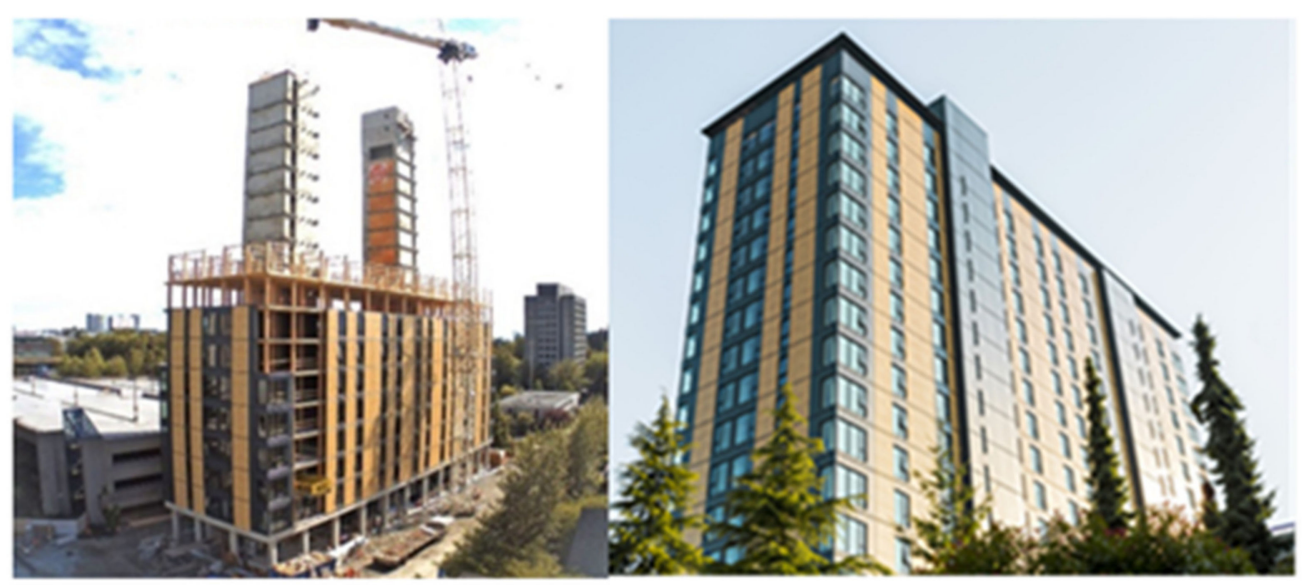

(a)

(b)

Figure 19. UBC Brock Commons, during construction (a) and after completion (b).

The UBC Brock Commons Student Residence (Figure 20), herein also referred to as the UBC Tall Wood Building (TWB), was one of the winners of the "Tall Wood Building Demonstration initiative", launched in 2013 by Natural Resource with the requirement to use mass-timber products in structures of at least 10 stories tall. The 18-story building has a total building height of $58.5 \mathrm{~m}$ at the top of elevator parapet, with a typical story height of $2.8 \mathrm{~m}$ and a gross floor area of $840 \mathrm{~m}^{2}(15 \mathrm{~m} \times 56 \mathrm{~m})$ and provides 404 beds distributed in single-bed studios or four-bed units located on floors 2 to 18.

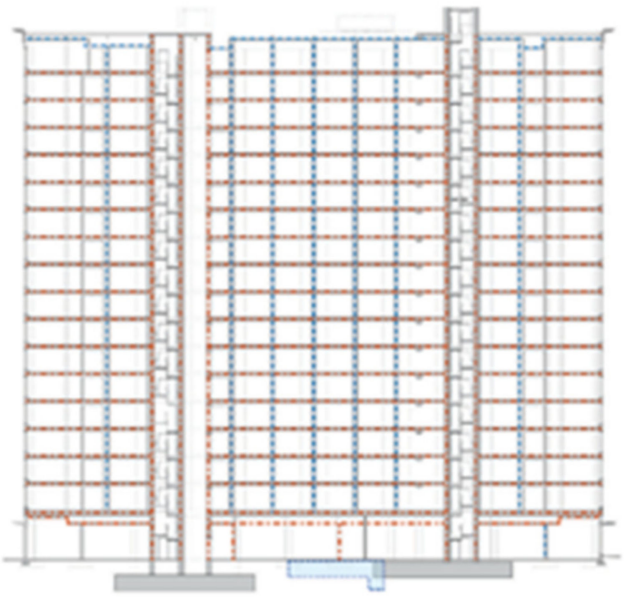

(a)

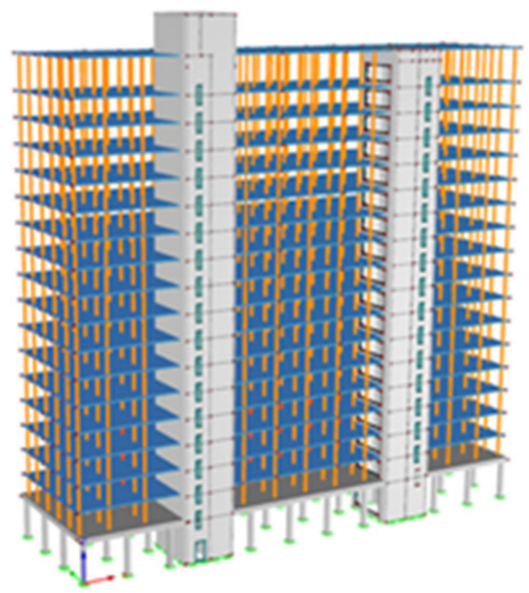

(b)

Figure 20. Building section (a) and structure with cores (b).

The building has a Hybrid structural system, i.e., made of combination of materials, in this case primarily concrete and wood (Figure 21). The two cores and the second floor are made of concrete, while the remainder of the structure is made of wood. The cores 
have 450-mm-thick cast-in-place reinforced concrete walls that resist the lateral forces on the building as well as providing the vertical circulation, housing stairs, and elevator shafts. The primary gravity frames include mass-timber columns (Parallam (PSL) for the highest loaded zones and glulam for the remainder) and a perimeter beam to support the building envelope.

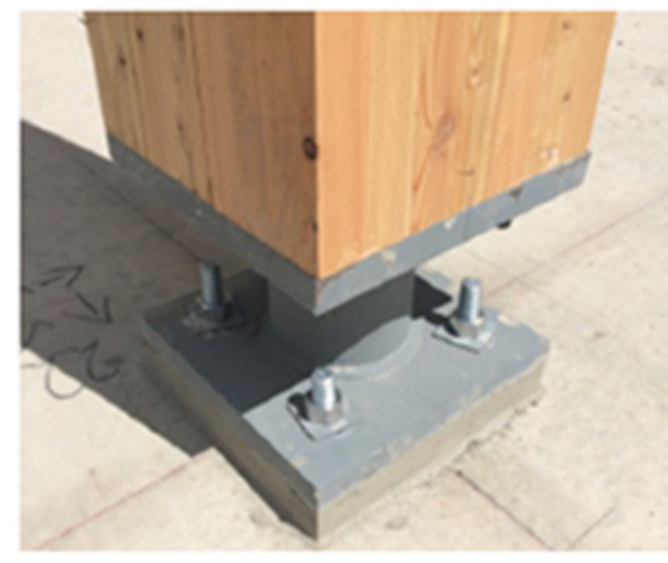

(a)

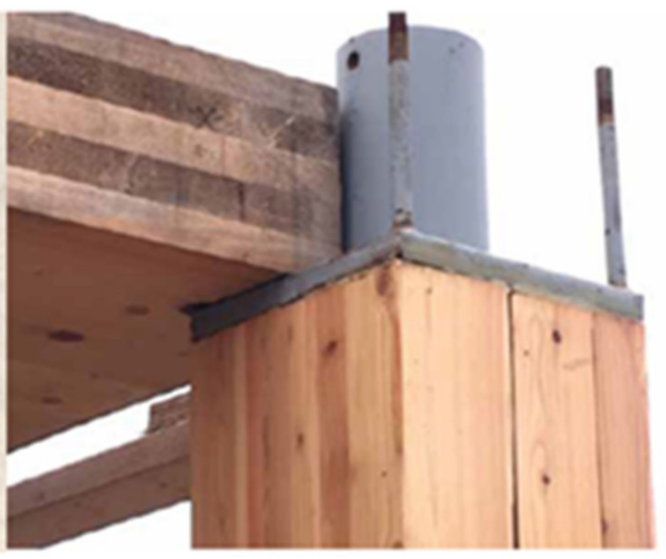

(b)

Figure 21. Column base connection (a) and floor support (b).

The concrete elements of the TWB are constructed using $35 \mathrm{MPa}$ concrete meeting the requirements of CSA A23.3 [2]. The engineered wood columns are of either PSL or glulam (Figure 21). There are three distinct column types: $72-265 \mathrm{~mm}$ by $265 \mathrm{~mm}$ PSL 2.2E type located on the interiors of floors 2 through $5 ; 624-265 \mathrm{~mm}$ by $265 \mathrm{~mm}$ D.Fir-L 16c-E glulam columns on floors $2-10$; and $630-215 \mathrm{~mm}$ by $265 \mathrm{~mm}$ D.Fir-L $16 \mathrm{c}-\mathrm{E}$ glulam columns on floors 11 to 18 . Isotropic linear elastic properties were assigned to the timber columns as they were subjected to axial load only.

The cross-laminated timber (CLT) floor panels are connected with $140 \mathrm{~mm} \times 25 \mathrm{~mm}$ plywood splines. The connections between the CLT floor panels and the concrete core is a steel ledger angle (L203 $\times 152 \times 13 \mathrm{LLH}$ ) welded to a 300-mm-wide embed plate cast in the core at every $1500 \mathrm{~mm}$ and then screwed to the CLT panels. Drag straps are used in core connections to ensure that lateral loads transfer. The straps are 100-mm-wide steel plates which vary between $6.4 \mathrm{~mm}$ and $12.5 \mathrm{~mm}$, depending on the floor level of the building, and between $1.5 \mathrm{~m}$ and $7.2 \mathrm{~m}$ in length depending on orientation, welded to faceplates that are anchored to the core. For the connections between columns and panels, a welded HSS and steel plate assembly was chosen since it satisfied these requirements. A $40-\mathrm{mm}$ concrete topping fills the space between the columns and the CLT panels.

The cradle-to-gate environmental impacts for each category and each layout are listed in Figure 22. The quantities are given in an equivalent unit. For example, kilograms of carbon dioxide are used as an equivalent unit to measure global warming potential. Figure 23 illustrates the difference in impacts for each layout using the existing building as a baseline. That is, Layout 1 concrete has 100\% impact for all categories. 


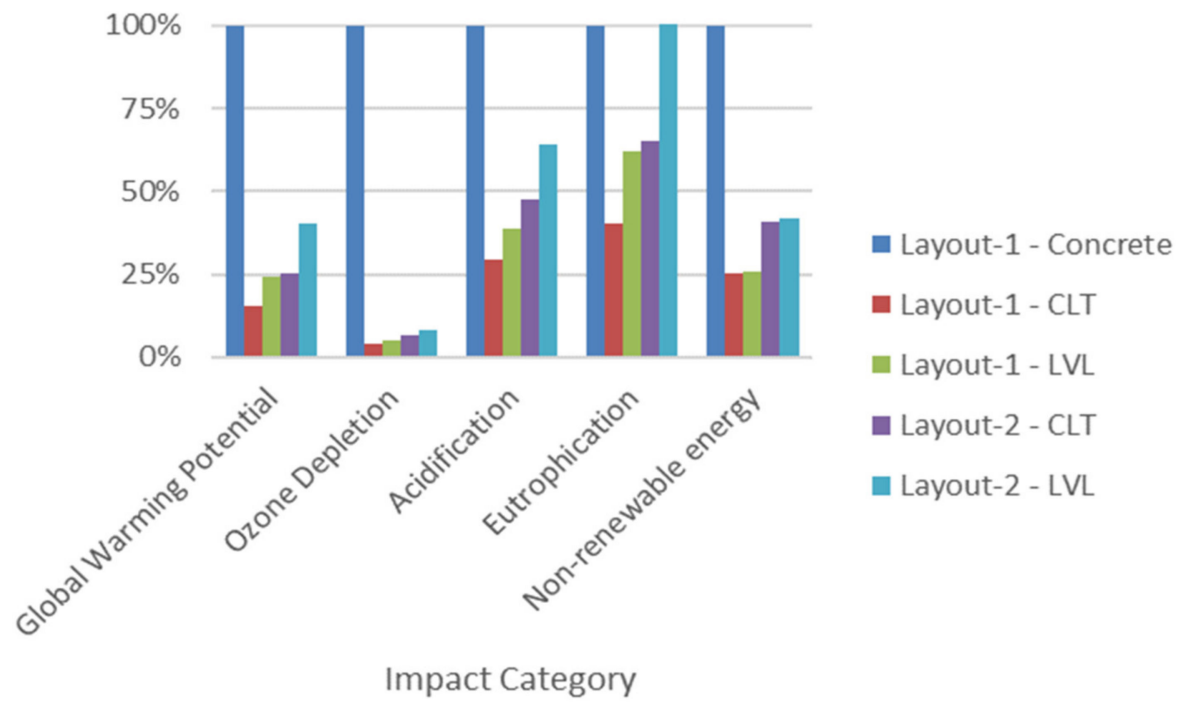

Figure 22. Comparison of impact categories (cradle-to-gate).

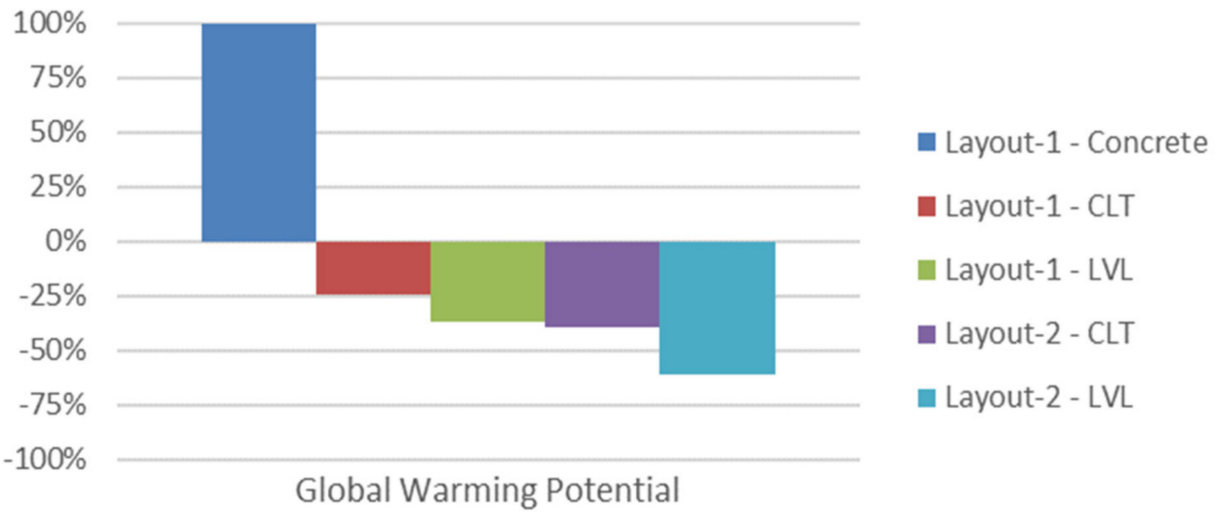

Figure 23. Comparison of global warming potential (cradle-to-grave).

When analyzing the environmental effects of timber, including the effects that occur beyond the building life have a significant impact on the global warming potential. This is because wood sequesters carbon from the atmosphere [5] at the end of its useful life in the building. Figure 23 shows that the global warming potential for the mass-timber layouts is a net negative, that is, using the mass-timber reverses the effects of global warming due to carbon sequestration. For the concrete cores, including the impacts beyond the building life increases the global warming potential. Note that the cradle-to-grave impact assessment causes no significant change in the other four impact categories.

Analyzing the results from Athena Impact Estimator for Buildings, it is evident that the use of mass-timber cores in place of concrete has significant environmental benefits for the UBC TWB. Regarding the cradle-to-gate impacts, the concrete core building has the highest impact in all but one category when compared to the mass-timber layouts. Layout-2 with LVL walls has a 3\% higher eutrophication potential when compared to the layout-1 with concrete, however, it is significantly lower in all other impact categories. For the mass-timber layouts, the more material used, the higher the environmental impact of the building. Conversely, when looking at the effects beyond the building life (cradle-to-grave assessment) the larger volume of timber corresponds with a decrease in global warming potential. This is due to the carbon sequestration of the wood.

In conclusion, it is clear that the use of a mass-timber LLRS for the UBC TWB would have significant environmental benefits with regard to the five impact categories recognized by LEED $\mathbf{v}$. 


\section{Case Study II: Tall Wood-Concrete Hybrid Building}

A concrete (Figure 24a) and a hybrid building (Figure 24b,c) were investigated to compare their LLRS and the material amount required to meet structural demands of Part 4 of NBCC (2015). The buildings were designed for Vancouver, BC using the data from NBCC 2015. Both the concrete and hybrid buildings had plan dimensions of $27 \mathrm{~m} \times 27 \mathrm{~m}$ with $303-\mathrm{m}$-tall stories for a total building height of $90 \mathrm{~m}$. The structural system for the concrete building consists of perimeter gravity columns that support a flat plate slab system and a center elevator/stairwell core that supports the slab and resists the lateral wind and seismic loads. The hybrid buildings eliminated two out of every three flat plate slab systems and implemented the glulam beam and CLT floor system. This system carried the gravity loads and transferred them to the perimeter concrete columns and the center concrete core similar to the flat plate slab. The façade and foundation design were not part of this projects' scope. Two different glulam beam and CLT floor systems are compared for the hybrid building. One system with a $4.5 \mathrm{~m}$ on-center beam layout with one-way spanning CLT panel system and one with a 3-m on-center beam layout with two-way spanning CLT panels.

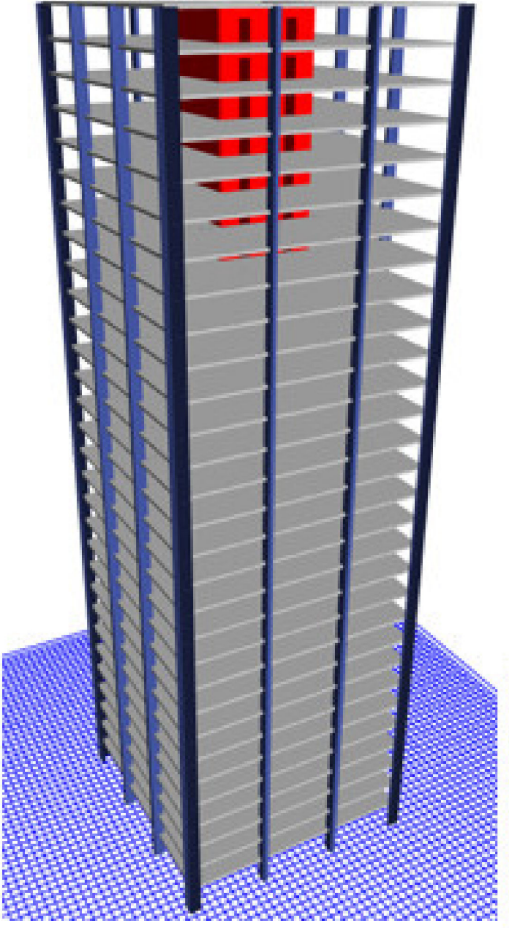

(a)

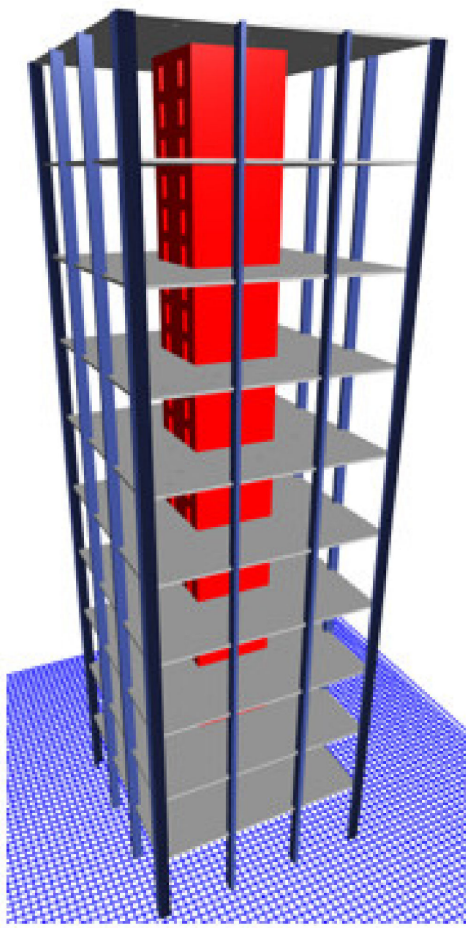

(b)

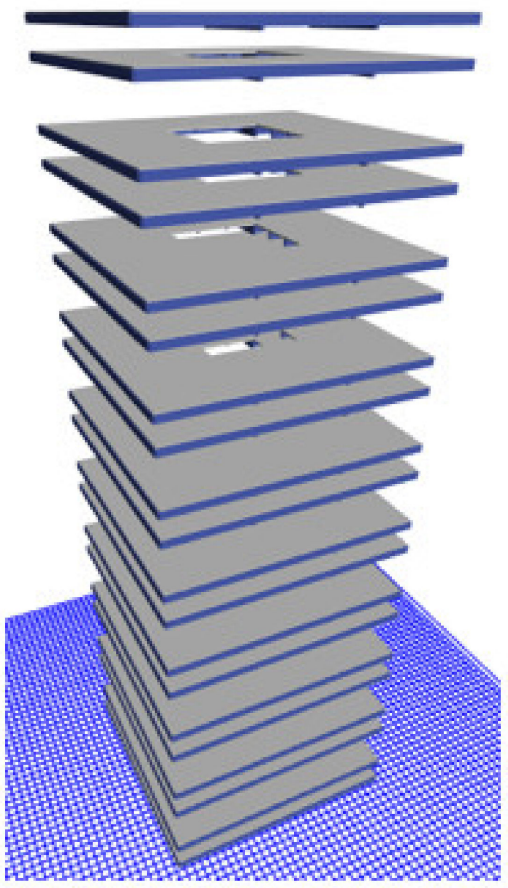

(c)

Figure 24. (a) Concrete building; (b) concrete elements of hybrid building; (c) timber floors of hybrid building.

A partial Environmental Impact Assessment (EIA) was performed using Athena Impact Estimator for Buildings (Athena 2018). Material properties, weights, and volumes were exported from ETABS into Athena to calculate values to compare the three buildings. The control location for this comparison was set to Vancouver, BC, the same as the climatic data for the structural analysis. In this EIA comparison, only the superstructure of the three buildings is assessed; the foundation, architectural components, building envelope materials, and operational energy are not in the scope of this project, and therefore this is not a Life Cycle Assessment (LCA). The concrete building has a Bill of Materials (BOM) exclusively as volumes of concrete for the columns, flat plate slab, and core walls. The two hybrid buildings have additional Douglas-Fir glulam beams and S-P-F CLT panels.

The reporting format based on the area of the building's life cycle that is used by the Athena Impact Estimator for Buildings software to analyze the results, based on the EN 
15804 (212). Only modules A, C, and D, which include material extraction, processing, construction process, end of life deconstruction, and beyond building life recycling or reuse, are analyzed by Athena. The structural materials for the buildings are converted into equivalent environmental impact masses of kilograms of $\mathrm{CO}_{2}$ for global warming potential and kilograms of $\mathrm{O}_{3}$ for smog potential.

Setting the concrete building as the baseline for the BOM comparison it is shown that the hybrid buildings use significantly less concrete for the structural system. The columns used as the gravity system are the same cross section for all three buildings. Incorporating mass timber elements eliminates two thirds of the flat plate slabs and allows the concrete core wall thicknesses to be reduced. The two-way CLT floor system building is used as the baseline for timber material mass comparison because it has a higher quantity of materials than the one-way CLT floor system. Using the CLT as a one-way spanning floor system allows for a thinner panel section and less supporting beams, which makes it the more material efficient choice for this building layout.

Figure 25 compares the global warming and smog potential of the three different types of buildings with the concrete building set as a baseline. The two hybrid building systems produce nearly half the amount Global Warming Potential (GWP) and approximately three quarters of the Smog Potential (SP) as the concrete building during the material extraction, production, and construction phases. This confirms that the production of cement for concrete has a significantly higher environmental impact than using wood materials. At the end of the life cycle, mass timber elements are easier and require less energy to disassemble than reinforced concrete as presented in the end-of-life bar chart in the tables. Producing a hybrid building while utilizing both materials for their strengths is shown to have a positive effect on the environmental impact a building can have by using less than half of the concrete and integrating the much lighter carbon-storing mass timber elements.

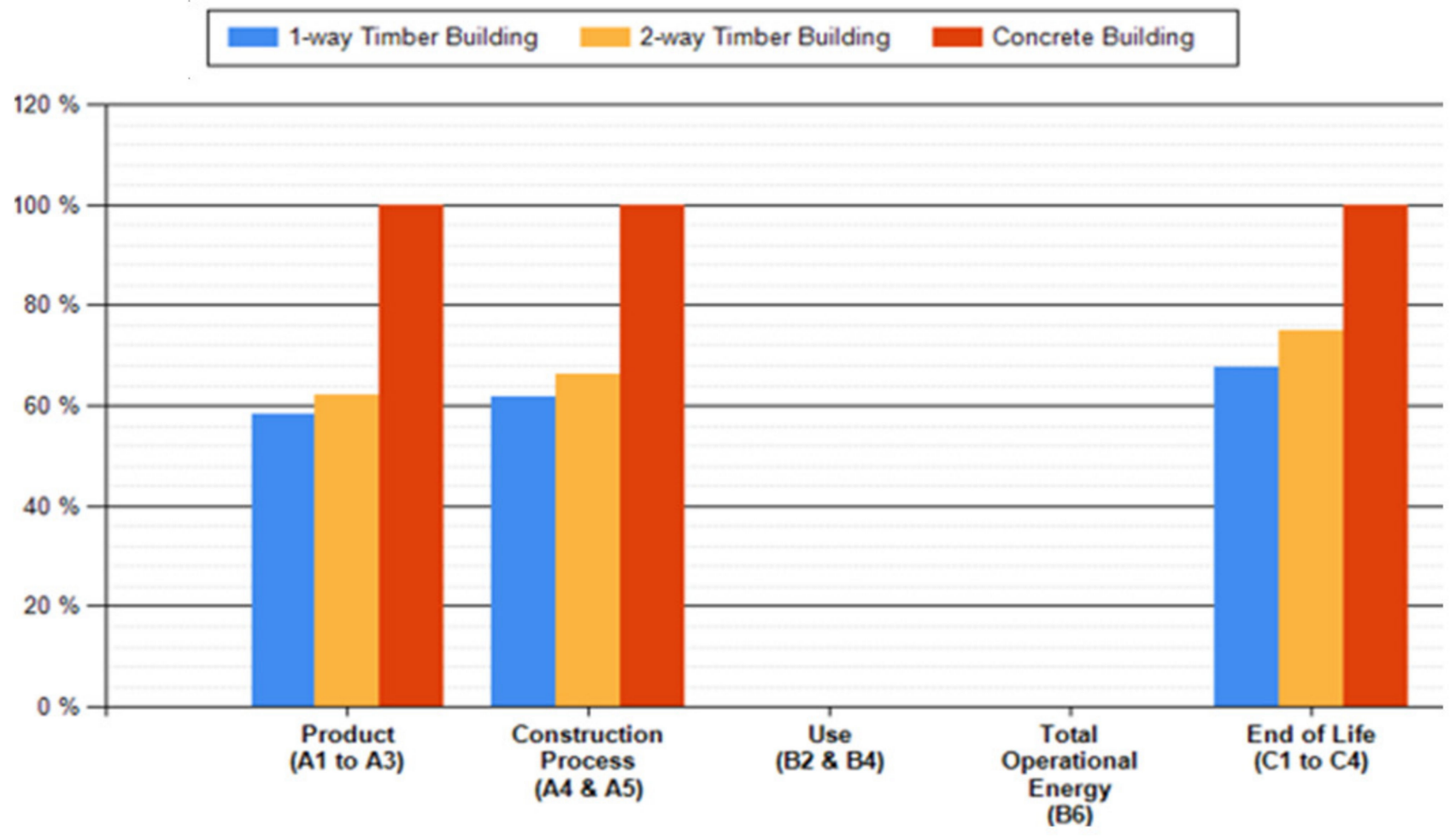

Figure 25. Global warming potential by life cycle stage, normalized to concrete building.

This substitution of two of every three concrete floors with mass timber is based on the target location of China, where the current building code limits wood construction to three stories. Substituting two out of every three concrete floors reduces the number of concrete pours, the amount of formwork, and the curing time, hence speeding up onsite 
building erection time. This paper demonstrates that a 30-story building can be designed by substituting a significant amount of concrete with mass timber. Wood materials are renewable, making them more environmentally friendly, and have a much higher strength to weight ratio that concrete. The hybrid building mass was greatly reduced by integrating lighter timber elements, resulting in much lower gravity and seismic load demands on the structural system. Reducing the building mass allows the use of thinner concrete core walls for the LLRS while maintaining the lateral drift limits as per NBCC 2015. Unlike the concrete building, where the core thickness was governed by the ULS design for shear rebar reinforcement, the hybrid buildings were governed by SLS for inter-story drift based on the wind loading.

The one-way CLT panel floor system and two-way CLT panel floor system layouts were compared because CLT can and is used in both applications. CLT is produced with the intent to be used as a two-way panel, however, production in BC is limited to a maximum of $3 \mathrm{~m}$ width, which limits floor layouts. Using a one-way system uses fewer supporting beams and a thinner CLT panel, resulting in less material. However, a one-way floor system could have a poorer vibration performance when compared to the two-way system. Using Dowel Laminated Timber for a one-way spanning floor system would result in a more material efficient system over using CLT as a one-way spanning floor. These analyses were not within this project's scope.

Integrating mass timber into the structural system resulting in the hybrid buildings reduces the quantity of concrete by $44 \%$ compared to the all-concrete building. The hybrid buildings cut down over half of the overall concrete required while only adding between 1300 to 1700 tons of mass timber. This shows a large reduction in the GWP by cutting down from 18,672 tons of total material to 9482 tons and 9858 tons for hybrid buildings. This EIA only scratches the surface of an LCA, and further investigation into building use and operational energy which is widely reflected on the building envelope and building location needs to be performed to obtain more accurate results. Expanding on this project, further investigations should be conducted on the connections between the structural elements and the constructability issues.

\section{Conclusions}

Sufficient understanding has been gained through collective research and development globally to use wood in lateral-force-resisting systems of mid-to-high-rise buildings. Among ongoing research in Europe and elsewhere, particular focus has been placed in North America on CLT building design for seismic loading. Current initiatives are looking into ways to apply performance-based seismic design to achieve resilient tall wood buildings in high seismic regions. Past and present initiatives from academia, research organizations, professional organizations, and industry groups, as well as regulatory bodies and government policies, are driving the movement forward.

Significant challenges, however, remain ahead particularly with commercial competitiveness and fire safety. The public perception of wood as a suitable material for this type of construction will be improved with each new application. Direct incentives such as demonstration projects and competitions should go a long way in removing barriers. With the continuation of the ongoing activities and favorable conditions, it can be expected that in the near future, wood will be established as one of the common materials to be considered for tall building construction in North America.

Funding: This research received no external funding.

Institutional Review Board Statement: Not applicable.

Informed Consent Statement: Not applicable.

Data Availability Statement: Not applicable. 
Acknowledgments: FPInnovations currently holds the intellectual property rights for Prestressed Timber in North America. Some of the research described here was financed by Structural Timber Innovation Company (STIC) - A research consortium jointly funded by the New Zealand and Australian government agencies and a number of wood products manufacturers from both countries. This research received no external funding. Some of the photos used were supplied by Andrew Buchanan, Professor Emeritus of University of Canterbury, Christchurch and Daniel Scheibmair, President of New Zealand Timber Design Society. Numerous others provided information on the projects discussed, all gratefully acknowledged.

Conflicts of Interest: The author declares no conflict of interest.

\section{References}

1. Fast, P.; Jackson, R. A Case Study for Tall Timber. Structure Magazine, June 2017; 50-52.

2. CSA. CSA O86: Canadian Standard for Engineering Design in Wood; CSA: Toronto, ON, Canada, 2020.

3. FPInnovations. Technical Guide for the Design and Construction of Tall Wood Buildings in Canada; FPInnovations: Pointe-Claire, QC, Canada, 2021.

4. Jones, R. Tall Wood Buildings: The Canadian Experience, Towards Taller Wood Buildings Symposium; WoodWorks Wood Products Council: Chicago, IL, USA, 2014.

5. Breneman, S.; Podesto, L. Timber skyline: A review of structural systems for high-rise wood structures. In Proceedings of the Structural Engineers Association of California Convention, Sacramento, CA, USA, 18-21 September 2013.

6. Holt, R. Survey of International Tall Wood Buildings; Summary Report for Forest Innovation Investment; Canada and Binational Softwood Lumber Council: Surrey, BC, Canada, 2014.

7. Sellen Construction. CLT Modular Construction: Residential Opportunities; Report Presented to Lake Union Partners; Sellen Construction: Seattle, WA, USA, 2013.

8. Schmidt, J.; Griffin, C.T. Barriers to the Design and Use of Cross-Laminated Timber Structures in High-Rise Housing. In Proceedings of the 2nd International Conference on Structures \& Architecture (ICSA2013), Guimaraes, Portugal, 24-26 July 2013.

9. Gagnon, S.; Pirvu, C. CLT Handbook-Cross-Laminated Timber, Canadian Ed.; Special Publication SP-528E; FP Innovations: PointeClaire, QC, Canada, 2011; ISBN 978-0-86488-547-0.

10. Kibert, C.J. Green buildings: An overview of progress. J. Land Use Environ. Law 2018, 19, 491-502.

11. Popovski, M.; Pei, S.; van de Lindt, J.W.; Karacabeyli, E. Force modification factors for CLT structures for NBCC. In Materials and Joints in Timber Structures; Springer: Berlin/Heidelberg, Germany, 2014; pp. 543-553.

12. Pei, S.; van de Lindt, J.W.; Popovski, M.; Berman, J.W.; Dolan, J.D.; Ricles, J.; Sause, R.; Blomgren, H.; Rammer, D.R. CrossLaminated Timber for Seismic Regions: Progress and Challenges for Research and Implementation. J. Struct. Eng. 2016, 142, E2514001. [CrossRef]

13. ASCE. Minimum design loads for buildings and other structures. In American Society for Civil Engineers; ASCE: Washington, DC, USA, 2010.

14. NEHRI. Planning/Collaborative Research: Engineered Timber Structural Systems for Seismically Resilient Tall Buildings. 2016. Available online: http:/ / neesclt.mines.edu/index.html (accessed on 5 September 2021).

15. USDA. 2014 Tall Wood Building Prize Competition. Available online: https://www.usda.gov/media/blog/2014/10/10 / announcing-us-tall-wood-building-prize-competition-innovate-building (accessed on 5 September 2021).

16. Robinson, T.; Hallova, A.; Spiritos, J.; Roelefs, M. New heights for renewables: The US Tall Wood Building competition. CTBUH J. 2016, 1, 26-31.

17. Robinson, T. Framework Portland, the All-Wood First High-Rise Building in North America; International Holzbau Forum: Garmisch, Germany, 2017.

18. Abrahamsen, R.B.; Malo, K.A. Structural design and assembly of "Treet"-A 14-storey timber residential building in Norway. In Proceedings of the World Conference on Timber Engineering, Quebec City, QC, Canada, 10-14 August 2014.

19. Abrahamsen, R.B. Mjøstårnet-Construction of an $81 \mathrm{~m}$ tall timber building. In Proceedings of the 23rd Internationales HolzbauForum, Garmisch, Germany, 6-8 December 2017.

20. Zhang, X. Seismic Design of Timber Steel Hybrid High-Rise Buildings. Ph.D. Thesis, University of British Columbia, Vancouver, BC, Canada, 2017.

21. Almufti, I.; Wilford, M. REDi ${ }^{\mathrm{TM}}$ Rating System: Resilience-Based Earthquake Design Initiative for the Next Generation of Buildings; ARUP: London, UK, 2013.

22. Iqbal, A.; van de Lindt, J.; Pei, S.; Dao, T.; Bahmani, P.; Barbosa, S.; Popovski, M. Recent Progress in North American Research on Seismic Resilient Wood Buildings. In Proceedings of the 17th U.S.-Japan-New Zealand Workshop on the Improvement of Structural Engineering and Resilience, Queenstown, New Zealand, 14 November 2018.

23. Blomgren, H.-E. A proposed solution for buildings in regions of high seismicity. In Mass Timber Research Workshop; USDA Forest Products Laboratory: Madison, WI, USA, 2015. 
24. Blomgren, H.-E.; Koppitz, J.-P.; Valdés, A.D.; Ko, E. The heavy timber buckling-restrained braced frame as a solution for commercial buildings in regions of high seismicity. In Proceedings of the World Conference on Timber Engineering, Vienna, Austria, 22-25 August 2016.

25. Iqbal, A.; Pampanin, S.; Buchanan, A. A General Design Approach for Post-Tensioned Timber Subassemblies. J. Earthq. Eng. 2019. [CrossRef]

26. Park, R.; Paulay, T. Reinforeced Concrete Structures; John Wiley \& Sons, Inc.: Hoboken, NJ, USA, 1975.

27. Connolly, T.; Loss, C.; Iqbal, A.; Tannert, T. Feasibility Study of Mass-Timber Cores for the UBC Tall Wood Building. Buildings 2018, 8, 98. [CrossRef] 